\title{
A Three-Dimensional Numerical Investigation of Dynamic Fracture Characteristics of Rock Specimens with Preexisting Surface Flaws
}

\author{
XiKun Qian $\mathbb{D}^{\text {, }}$, ZhengZhao Liang $\mathbb{D}$, and ZhiYi Liao \\ State Key Laboratory of Coastal and Offshore Engineering, Dalian University of Technology, Dalian 116024, China \\ Correspondence should be addressed to ZhengZhao Liang; liangzz@dlut.edu.cn
}

Received 11 May 2018; Accepted 8 August 2018; Published 18 October 2018

Academic Editor: Fengqiang Gong

Copyright @ 2018 XiKun Qian et al. This is an open access article distributed under the Creative Commons Attribution License, which permits unrestricted use, distribution, and reproduction in any medium, provided the original work is properly cited.

\begin{abstract}
FEM-based numerical investigation was conducted to investigate the fracture characteristics of heterogeneous rocks with preexisting surface flaws under dynamic loadings. Different types of cracks from initiation to coalescence of the specimen with a single flaw were reproduced in numerical tests, which were very highly agreed with experimental results. Numerical testing on specimens with a single flaw demonstrated that the crack behaviors, including its path, length, and cracking velocity, were significantly different on the surface of and inside the rock specimen. In addition, the higher the incident pressure level applied, the longer the cracking distance propagated; the more the AE count is, the larger the AE energy released and the greater the fragmentized. Furthermore, the cutting depth of flaw could significantly affect crack propagation patterns and AE characteristics. When the cutting depth of flaw is equal to the thickness of the specimen, there would be no shell-like crack emerged. Subsequently, testing results of the multi-preexisting flaws indicated that the surface flaws on the specimen made the crack initiation and coalescence behaviors more complicated. The coalescence between flaw tips is not easy, and the coalescence of preexisting flaws needs two or multiple cracks to achieve. The coalescence points occurred not only in the preexisting flaw but also in the trajectory of the wing cracks and antiwing cracks. The accumulative AE energy and AE counts are positively correlated with the amounts of preexisting flaws. Finally, crack evolution under dynamic and static loading was compared. Short tensile cracks are found to be the most common crack type, which are responsible for specimen failure. These findings could give a better explanation on the crack initiation and propagation of rock specimen with preexisting flaw, which is the phenomenon that has not been observed in many dynamic experiments.
\end{abstract}

\section{Introduction}

The response of rocks under dynamic loading is of great significance for rock engineering, which directly affects the structural stability. The failure of heterogeneous rock under dynamic loading is commonly associated with crack propagation along preexisting defects and is related to initiation and accumulation of new cracks. Fractures normally exist in many rock engineering projects, and they generally expose on the surface of rock masses, which can be treated as surface fracture in three dimensions. The surface flaw was the widespread type of crack; therefore, systematic study on the mechanisms of crack initiation and propagation process in rocks with existing surface flaws under dynamic loading is important for rock engineering, mining engineering, and earthquake prediction $[1,2]$.

In recent decades, many experimental investigations have been conducted to study the mechanical properties of rocks under dynamic loading [3-10]. In research examining accurate dynamic characterization of rock test, one of the controversial topics is the loading rate effects. Generally, researchers hold the opinion that the loading rate has effects on the strength of rocks [11-14]. With an increase in the loading rate, rock dynamic compressive strength presents a significant increase. Liao et al. $[15,16]$ adopted the FEMbased numerical code rock failure process analysis (RFPA) to simulate the damage and failure of rock materials under dynamic loading. They investigated the effects of different 
designs of the rock specimen, which will further significantly affect the testing results. Meanwhile, many researchers investigated the influence of loading rate on the dynamic mechanical properties, and it has been revealed by extensive experiments that fragmentation of rocks is obviously related to the loading rate [17-19].

However, few studies paid attention to the dynamic crack propagation behavior in rock-like material specimens with preexisting flaws. Jiang et al. [20] investigated in detail the dynamic crack coalescence of the $3 \mathrm{D}$ printed specimens with preset cracks during SHPB tests. They captured the crack pattern and dynamic behavior of the specimen with multiflaws. Li and Zhou carried out dynamic impact tests using a modified split-Hopkinson pressure bar device with the aid of a high-speed camera to study the cracking process and failure of rocks containing a single flaw. They found that cracking involves two major stages: the formation of white patches and development of macrocracks. Wang et al. [21] observed the dynamic crack behavior due to the impacting of the drop hammer on the defective PMMA medium of manufactured hole defect using the test system of digital laser dynamic caustics. The stress intensity factor and velocity at the running crack tips were analyzed and concluded that the influence of empty hole defects of brittle materials on dynamic fracturing is great. In addition, Zou et al. [22] investigated the failure behavior of rock specimens with a single preexisting flaw under dynamic loading during SHPB tests. It is found that the compressive strength, the nominal elastic modulus, and the failure strain of the gypsum specimens increase apparently with the strain rate, and shear cracks are observed to be the dominant crack types under dynamic loadings.

Owing to the nontransparent nature of rocks, it is hard to trace the initiation and propagation of fractures in the laboratory. Although some new techniques, such as the CT scanning and 3D printing technology and acoustic emission detection technology, are adopted to observe the failure process [23], it is too expensive to perform a large number of such experiments. Numerical methods present an alternate way to investigate the fracturing of cracks in rock and rocklike materials, which has the advantage over the experimental method in capturing the crack propagation inside the rock sample, obtaining the stress/strain distribution of the rock sample and avoiding some errors in laboratory. Liang et al. [24] (2014) developed RFPA ${ }^{3 \mathrm{D}}$, which is an extension of $\mathrm{RFPA}^{2 \mathrm{D}}$ to investigate the initiation, propagation, and coalescence of $3 \mathrm{D}$ cracks. Its advantage is to handle material heterogeneity, nonlinearity, and boundary and simulate the $3 \mathrm{D}$ fracture in rock-like material. However, as far as the numerical simulation of $3 \mathrm{D}$ dynamic surface fracture is concerned, little information has been reported in the literature. In dynamic aspect, $\mathrm{Li}$ and Wong [25] studied the influence of loading conditions on the cracking process and type of propagation based on the finite element method and nonlinear dynamics. They concluded that shear cracks are initiated prior to the tensile cracks under a high loading rate. Further research in many numerical methods would be of great help in rock dynamic characteristics [5, 26, 27]. For instance, Yang et al. [28, 29] numerically researched the cracking patterns of rocks with a preexisting crack subjected to dynamic loading. They pointed out that the crack propagation could be affected by the applied loading, rock tensile strength, and rock heterogeneity.

In this study, $\mathrm{RFPA}^{3 \mathrm{D}}$ _Dynamic numerical analysis tool is used to investigate the $3 \mathrm{D}$ fracture process of rocks containing preexisting surface flaws. Firstly, fracturing process of rocks with a single preexisting surface flaw was preferentially modeled. The characteristics of crack initiation, propagation, and coalescence both on the surface of and inside the rocks were investigated in detail. Subsequently, influences of the amplitude of incident pressure and the cutting depth of surface flaw were analyzed. Moreover, analysis on the multi-preexisting surface flaws was numerically carried out to point out the effect of their interactions on the crack initiation, propagation, and coalescence. Finally, different cracking behavior of the specimen with a single surface preexisting flaw under dynamic and static loading is discussed. And the velocity of the wing cracks and shell-like cracks is also investigated.

\section{Methods}

2.1. Brief Description of $R F P A^{3 D}$. In this study, an FEMbased numerical tool, rock failure process analysis (RFPA) code, was used to simulate the failure process of rocks with preexisting flaws $[24,30]$. However, we know that the rock is a heterogeneous material filled by the disorder of microstructures, which plays a significant role on the mechanical properties of rock [16]. Therefore, the rock heterogeneity should be considered and implemented in the numerical model. The rock heterogeneity can be well characterized by using the statistical method. In RFPA ${ }^{3 \mathrm{D}}$, the numerical testing sample is composed by elements which have exactly the same shape and size. It is assumed that the distribution of elemental mechanical parameters, including the strength, Poisson ratio, elastic modulus, and density, can be depicted by the Weibull distribution function, as follows:

$$
\phi(\alpha)=\frac{m}{\alpha_{0}} \cdot\left(\frac{\alpha}{\alpha_{0}}\right)^{m-1} \cdot e^{-\left(\alpha / \alpha_{0}\right)^{m}},
$$

where $\phi(\alpha)$ is the statistical distribution density of a mechanical property $\alpha ; m$ defines the shape of the Weibull distribution function, named "heterogeneity index"; $\alpha$ is the mechanical parameter of element, e.g., the strength, elastic modulus, Poisson ratio, and weight; and $\alpha_{0}$ refers to the average of the element parameters. According to the Weibull distribution, with increasing $m$, the rocks tend to be homogeneous.

Due to the wide application of RFPA, other detailed principles can be found in Zhu et al. [6] and Liang et al. [24].

2.2. Calculation of Crack Speed. The speed of crack propagation is a significant characteristic for dynamic crack propagation in theoretical studies and engineering applications. According to a study by Suzuki et al. [31], the speed of crack propagation can be expressed as the speed in a certain direction when the crack branching or curving 
angle is relatively small. Figure 1 demonstrates the method for calculating the crack propagation velocity, where $s_{1}$ and $s_{2}$ refer to the crack propagation distance before and after branch and $\tau_{1}$ and $\tau_{2}$ correspond to the consumption time of $s_{1}$ and $s_{2}$. The crack length $s_{1}$ and $s_{2}$ are the propagation distances of consumption time $t_{1}$ and $t_{2}$, respectively. Especially, the crack length $\tau_{2}$, as shown in the schematic diagram, shows that the crack curving or branching angle cannot be always ignored and expressed by the distance in the vertical or horizontal direction but can also be applied to this method. Therefore, the crack propagation velocity is meant for a certain macro select crack, and the propagation of select crack requires continuity. To ensure the accuracy of the calculating result, the time interval would be shorter in a certain time range, especially the moment when the crack curving and branching [28]. The velocity of crack propagation can be expressed as follows:

$$
v=\frac{s}{t}
$$

where $t$ is the time interval and $s$ is the crack propagation distance in the time interval $t$.

\section{Numerical Model Setup}

Ten groups of numerical tests were prepared to investigate $3 \mathrm{D}$ rock failure process under dynamic loading, as detailed in Table 1. Figure 2(a) shows the setup of numerical models and all the incident compressive stress waves directly applied on the top of specimens. Moreover, a free reflected boundary is adopted on all the boundaries of the specimen, and the supporting end of the specimen is fixed to simulate the SHPB tests under ideal conditions. The length, width, and height of the specimens are $80 \mathrm{~mm}, 40 \mathrm{~mm}$, and $40 \mathrm{~mm}$, respectively. The single preexisting flaw is set to be a semielliptic flaw that is embedded at the center of each specimen, as shown in model I. Half of the major axial diameter and minor axial diameter are set to $8 \mathrm{~mm}$ and $6 \mathrm{~mm}$, and the thickness of the flaw is $0.5 \mathrm{~mm}$. In these simulations, the initial mean values of the static compressive strength, elastic modulus, and Poisson ratio for all the elements are $99.6 \mathrm{MPa}$, $44.7 \mathrm{GPa}$, and 0.33 , respectively. The mesh size of the numerical model is $160 \times 80 \times 80$ with $1,458,000$ elements which, therefore, effectively reduce the required computer memory and computational time used to simulate an $80 \mathrm{~mm} \times 40 \mathrm{~mm} \times 40 \mathrm{~mm}$ rock mass.

In an attempt to more adequately reveal the response of specimens with the preexisting flaw under different dynamic loading conditions, three incident compressive stress waves as emerged in Figure 3 were considered in numerical simulation. These compressive stress waves are triangle compressive stress wave. All stress waves are $48 \mu \mathrm{s}$ in duration, but with different amplitude values.

The effect of flaw geometry on crack propagation and AE characteristic is analyzed with the single preexisting flaw specimen. In this article, only one flaw geometry parameter (the flaw depth) is considered, which is the minor axial diameter length. Detailed descriptions of specimens with

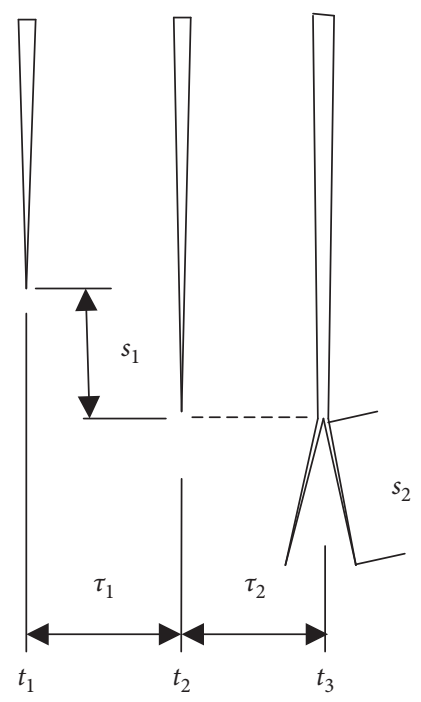

FIgURE 1: Schematic diagram for measurement of crack propagation speed.

TABle 1: Three flaw dip depths, model case, loading case, and homogeneity indices of rock are considered.

\begin{tabular}{|c|c|c|c|c|}
\hline $\begin{array}{l}\text { Case } \\
\text { number }\end{array}$ & $\begin{array}{c}\text { Cutting } \\
\text { depth } \\
\text { of flaw }(\mathrm{mm})\end{array}$ & $\begin{array}{l}\text { Homogeneity } \\
\text { index }\end{array}$ & $\begin{array}{l}\text { Model } \\
\text { case }\end{array}$ & Loading case \\
\hline 1 & 6 & $m=4$ & Model I & Loading caseI \\
\hline 2 & 6 & $m=4$ & Model I & $\begin{array}{c}\text { Loading } \\
\text { caseII }\end{array}$ \\
\hline 3 & 6 & $m=4$ & Model I & $\begin{array}{c}\text { Loading } \\
\text { caselII }\end{array}$ \\
\hline 4 & 6 & $m=4$ & Model II & Loading caseI \\
\hline 5 & 6 & $m=4$ & $\begin{array}{l}\text { Model } \\
\text { III }\end{array}$ & Loading caseI \\
\hline 6 & 20 & $m=4$ & Model I & Loading caseI \\
\hline 7 & 40 & $m=4$ & Model I & Loading caseI \\
\hline
\end{tabular}

different single flaw geometries are listed in Table 1. For example, case I denotes a single-flawed specimen with flaw depth $20 \mathrm{~mm}$ and angle $\alpha=45^{\circ}$.

In cases 5 and 6 , these rock specimens with two and three parallel preexisting flaws would be conducted as illustrated in models II and III, as shown in Figures 2(b) and 2(c). In multiflaw tests, parallel preexisting cracks lied at $45^{\circ}$ with a $10 \mathrm{~mm}$ crack spacing. The crack coalescence was simulated with the specimens containing multiflaws, which used for revelation those specimen failure mechanisms under dynamic loading, whose simulation experimental model geometry, material parameters, and meshing are the same with the single preexisting specimen.

According to a study by Liang et al. [24], preexisting fractures can be referred to as flaw, whereas initiated fracture can be referred to as cracks. Shell-like cracks in this study are distinguished from the wing cracks in the 2D study, which initiated at the inner contour of the existing flaw along loading direction. 


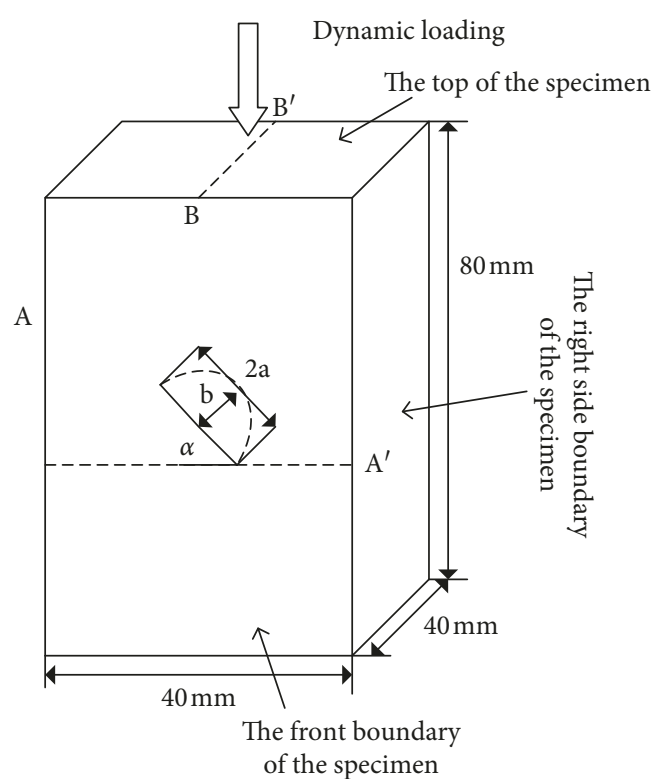

(a)

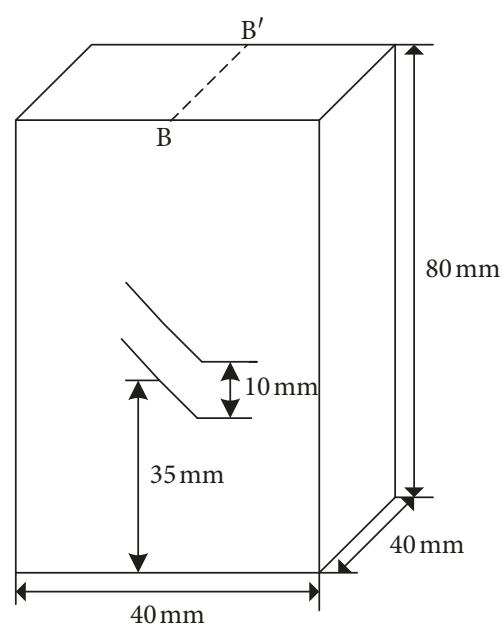

(b)

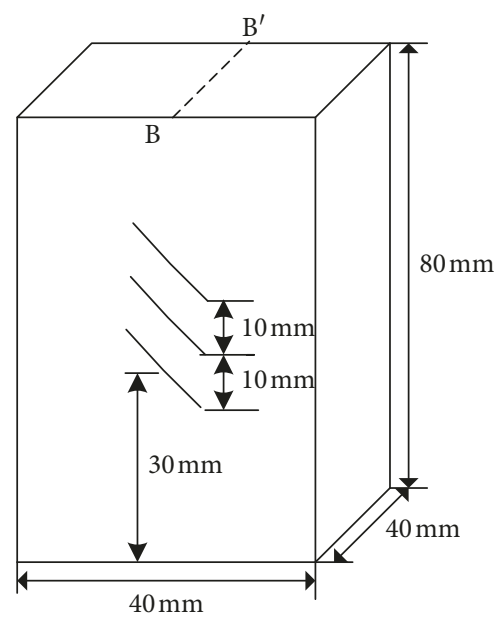

(c)

Figure 2: Numerical model of the rock specimen under dynamic loading conditions, where a, b, and c refer to the single flaw, two parallel flaws, and three parallel flaws. (a) The single flaw mode. (b) The two parallel flaws mode. (c) The three parallel flaws mode.

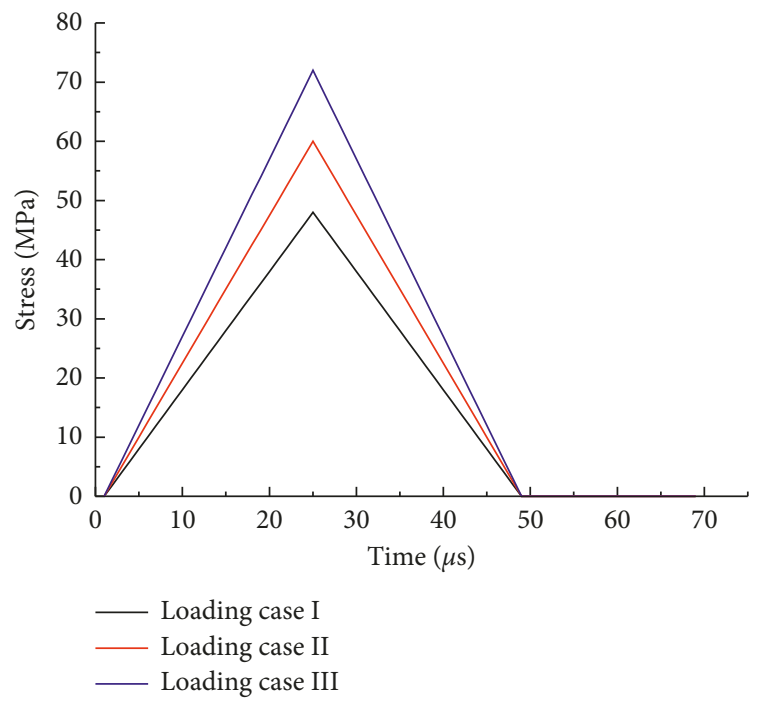

FIGURE 3: Dynamic impact compressive stress waves applied on the top surface of the specimen.

\section{Numerical Simulation on Dynamic Fracture of Rocks with a Single Preexisting Surface Flaw}

\subsection{The Rock Fracture Characteristic under Dynamic Loading}

4.1.1. The Crack Initiation and Propagation on the Surface of the Specimen. Figure 4 depicts the cracking sequence on the surface of the specimen from initiation to final failure with the preexisting flaw specimen under loading case I (case 1). Figure 5 presents the distribution of AE events at select time. In order to describe more clearly, the specimen is adjusted the view direction as instructed in the figure. For the $\mathrm{AE}$ events, the red circle refers to the shear failure, while the blue one stands for the tensile failure.

Based on the numerically simulated results, the failure process of the specimens that were subjected to dynamic compressive loading can be divided into four stages: the stage before crack initiation, the crack initiation stage, the crack propagation stage, and the final failure stage. During the first stage (about $t<30 \mu \mathrm{s}$ ), the displacement fields induced by the incident compressive waves at $t=20 \mu$ s for case 1 are shown in Figure 4(a), which demonstrated the propagation of stress waves and the AE events spatial distribution in the specimen. The AE counts randomly distributed inside the rock sample are induced by shear failure in this stage. It is interesting to note that the failure modes near the loading surface and preexisting surface flaw are significantly different, i.e., shear failure near the loading surface while tensile failure on the edge of the preexisting surface flaw. The authors believed that the shear failure near the loading surface is caused by discretely distributed weak elements while the tensile failure surrounding the surface flaw resulted from stress concentration. The reason for no crack is mainly because that the stress wave loading time is short, and the low stress cannot make the damaged elements to form a crack.

With the stress waves propagating, the specimen would enter the crack initiation stage after $t=30 \mu \mathrm{s}$. In this stage, the stress concentrated on the two tips of the preexisting flaw caused by the incident waves and then released when it reached the elementary capacity caused damage. Many damage elements were seen concentrated at the two tips of the preexisting flaw and wing cracks. It can be also seen that the $\mathrm{AE}$ events increase due to initiation of wing cracks around the preexisting flaw and are observed to concentrate 


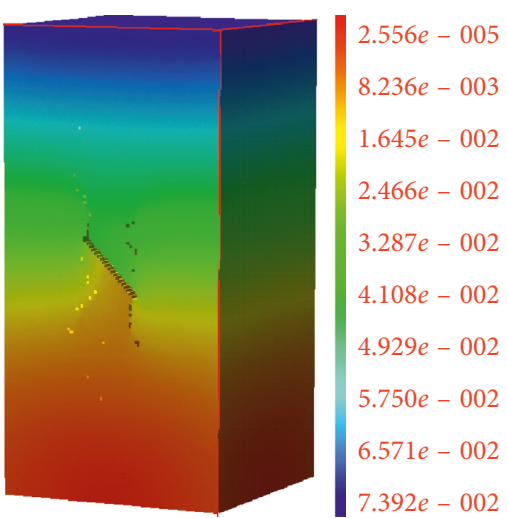

(a)

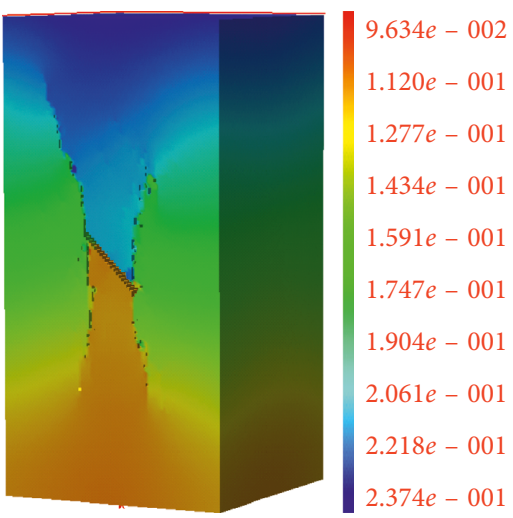

(c)

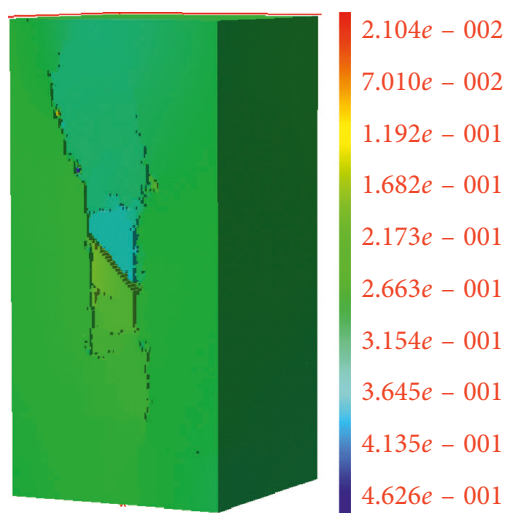

(e)

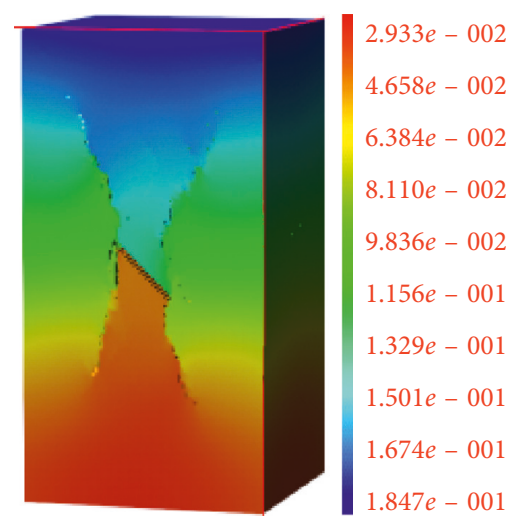

(b)

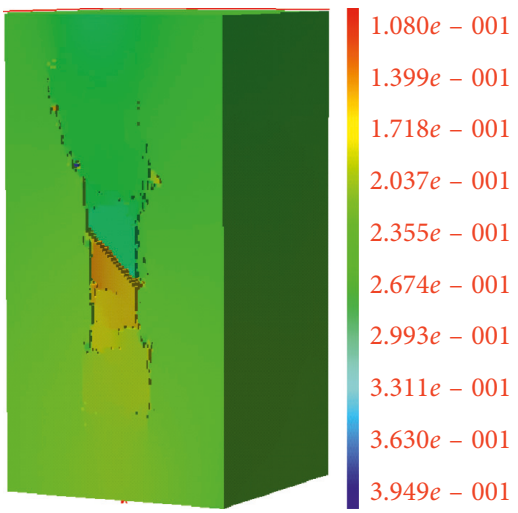

(d)

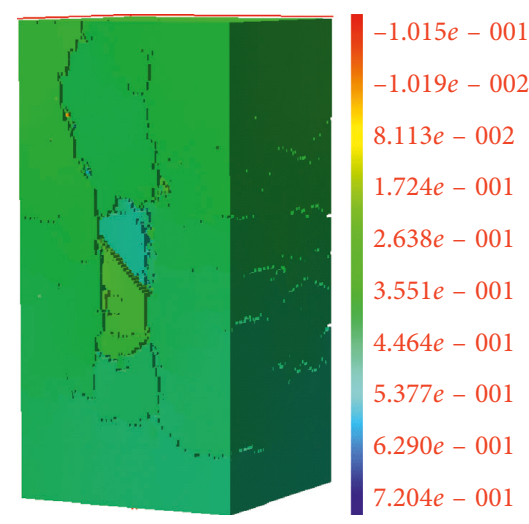

(f)

FIGURE 4: Numerical simulation of the $x$-axial displacement presents the crack behavior from initiation to failure mode at different select time: (a) $t=20 \mu \mathrm{s}$, (b) $t=30 \mu \mathrm{s}$, (c) $t=40 \mu \mathrm{s}$, (d) $t=45 \mu \mathrm{s}$, (e) $t=50 \mu \mathrm{s}$, and (f) $t=60 \mu \mathrm{s}$.

around the preexisting flaw mainly in the tensile mode. The wing crack initiated at the up tip propagated toward the top of the specimen, while the other one at the down tip to the bottom of the specimen.

The symbol to enter the propagation stage is the antiwing cracks are initiated at a certain distance from two tips of the preexisting flaw and rapidly propagated parallel to the loading direction around time $t=40 \mu \mathrm{s}$. When the antiwing cracks reached the tips of the preexisting flaw, the other end of the wing crack still propagated to the top or bottom of the specimen, which is approximately parallel to the loading direction. Meanwhile, the direction of wing cracks first changed to the right side specimen boundary, which was affected by the maximum principal stress. But, when $t=50 \mu \mathrm{s}$, the wing cracks returned to propagate to the loading direction again and the right tip of the wing cracks propagated to the specimen top at about time $t=60 \mu \mathrm{s}$ with no branching. AE events (or damaged elements) were observed to concentrate around the preexisting flaw mainly in the tensile mode, including the two tips of the flaw, where wing or antiwing cracks appeared apparently. With propagation of wing and antiwing cracks as well as the specimen inside crack initiation and propagation $(40 \mu \mathrm{s} \leq t \leq 60 \mu \mathrm{s})$, the $\mathrm{AE}$ events that damaged mainly in the tensile mode 


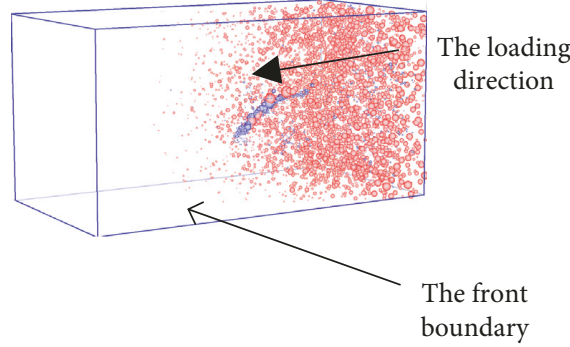

(a)

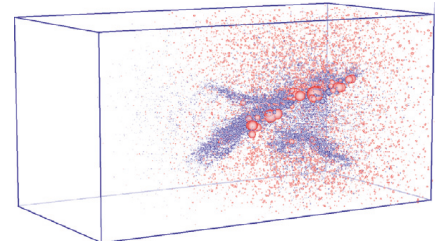

(c)

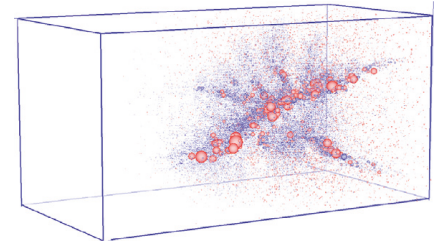

(e)
Y

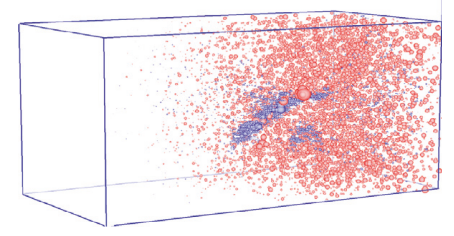

(b)

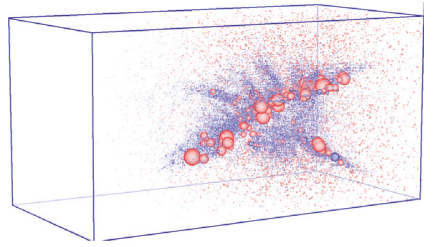

(d)

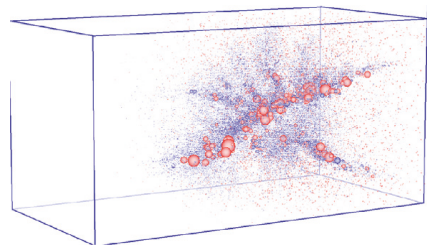

(f)

Figure 5: The distribution of AE at select time: (a) $t=20 \mu \mathrm{s}$, (b) $t=30 \mu \mathrm{s}$, (c) $t=40 \mu \mathrm{s}$, (d) $t=45 \mu \mathrm{s}$, (e) $t=50 \mu \mathrm{s}$, and (f) $t=60 \mu \mathrm{s}$.

increased gradually and were accompanied by a small amount of shear mode. From the crack behavior and AE event distribution in this stage, the specimen was in a complex stress state. The reason why wing cracks and antiwing crack propagation are different is due to the reflection of stress waves on the left and right sides and the presence of surface cracks. When the stress wave reached right and left side boundaries, it transfers to tensile stress wave and superposed with the subsequent wave. This also explained the elements mainly in tensile failure at this stage. The existing of superimposed stress wave altered the distribution of maximum principal stress resulting in a change in the propagation direction of the wing cracks. Nevertheless, the presence of preexisting flaw results in different stress states in the right upper and left down regions, which are the propagation area of antiwing cracks. In the right upper of flaw, because of the reflected waves from the preexisting flaw, it counteracted to alter the principal stress direction, which was caused by the superimposed wave on the left side boundary. While, in the left down area of the flaw, the preexisting flaw blacked the incident stress wave propagation caused this area had little superimposed stress wave. This also accounts for that the wing cracks and antiwing cracks above the preexisting flaw are longer than the corresponding cracks under the existing flaw. The elements were mainly in the tensile failure mode. It is noteworthy that a new type of cracking was observed propagating nearly perpendicular to the surface of the wing cracks with the stress wave propagation when time $t=50 \mu \mathrm{s}$. During the crack propagation stage ( $40 \mu \mathrm{s} \leq t \leq 60 \mu \mathrm{s})$, the wing cracks and antiwing cracks appeared and lead to " $\mathrm{X}$ " shape propagation mode as presented in Figure 4(f), which emerged in many rock dynamic experiments and articles [32-34] and 2014), as shown in Figure 6. This verifies the accuracy of the numerical simulation in this study in the survey of crack evolution.

In addition, a large number of short tensile cracks were observed to emerge when $t=60 \mu \mathrm{s}$, and the specimen appeared to be completely destabilized entering the final failure stage. These tensile cracks were due to the superposition of incident and reflected stress wave from the bottom of the specimen and caused the final failure mode. This phenomenon may also be another reason to explain the rock specimen appeared more fragmentation in experiment, which was conducted by Zou et al. [35]. The AE rate suddenly became substantially high as a result of a larger number of tensile cracks induced by the superposition tensile waves. The distribution of AE events was consistent with the failure pattern of a specimen with the preexisting flaw.

4.1.2. The Crack Initiation and Propagation inside the Specimen. In order to more expressly account for internal crack propagation, half of the specimen to the horizontal and vertical direction were cut away to observe the cross section of $\mathrm{A}-\mathrm{A}^{\prime}$ and $\mathrm{B}-\mathrm{B}^{\prime}$, as shown in Figure 2(a). Figures 7 and 8 describe the propagation process of cracks along slice $B-B^{\prime}$ and $\mathrm{A}-\mathrm{A}^{\prime}$, respectively. 

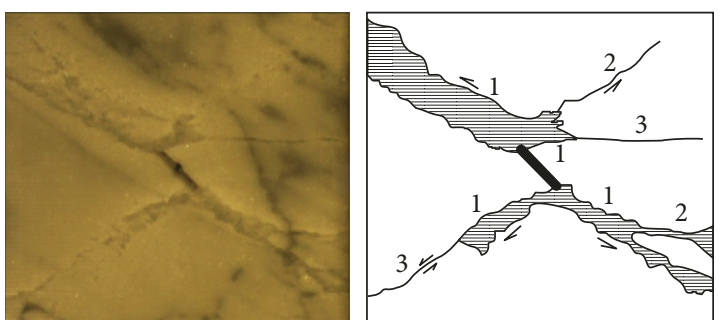

(a)

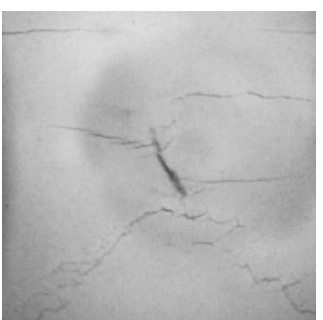

(b)

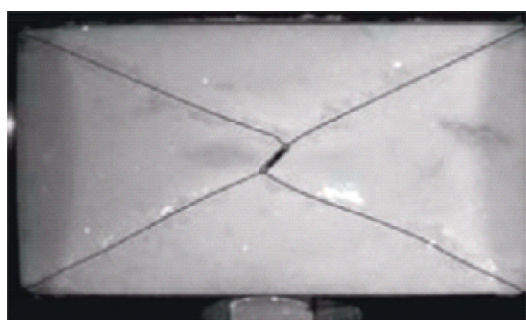

(c)

Figure 6: Failure modes under dynamic loading by (a) Li et al. [32] and (b) and (c) Zou et al. [33].

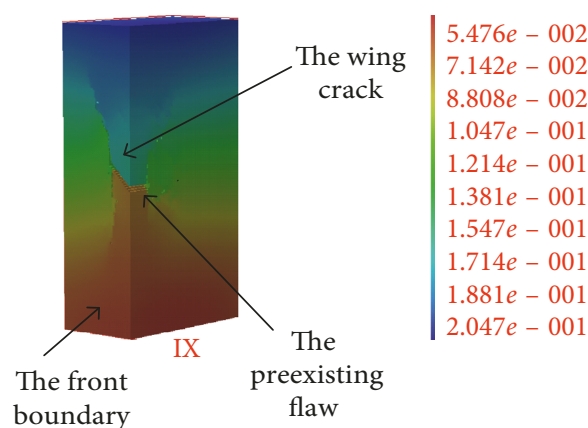

(a)

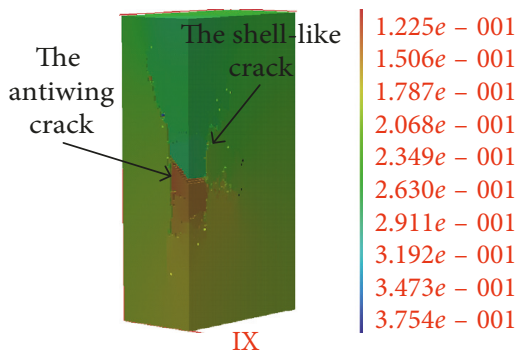

(c)

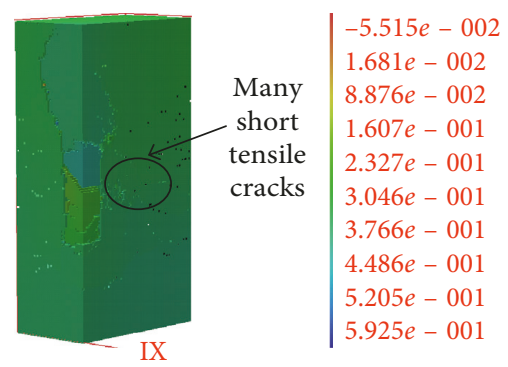

(e)

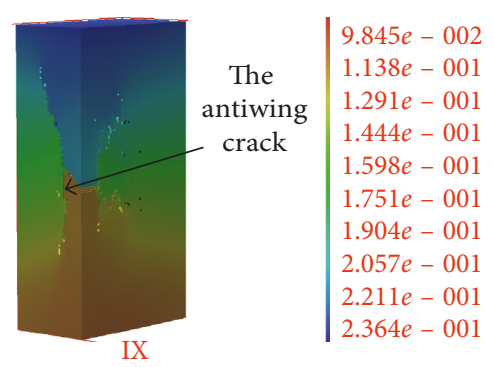

(b)

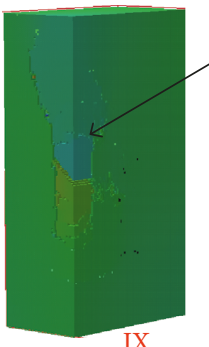

$$
\begin{array}{|l}
2.104 e-002 \\
7.011 e-002 \\
1.192 e-001 \\
1.683 e-001 \\
2.173 e-001 \\
2.664 e-001 \\
3.155 e-001 \\
3.645 e-001 \\
4.136 e-001 \\
4.627 e-001
\end{array}
$$

(d)

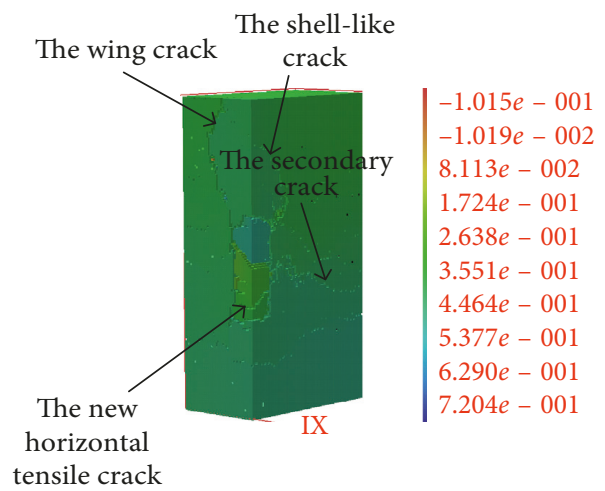

(f)

FIGURE 7: Plot of propagation of shell-like crack inside the rock specimen that contains the flaw of $45^{\circ}$ at different select time on section B-B': (a) $t=20 \mu \mathrm{s}$, (b) $t=30 \mu \mathrm{s}$, (c) $t=40 \mu \mathrm{s}$, (d) $t=45 \mu \mathrm{s}$, (e) $t=50 \mu \mathrm{s}$, and (f) $t=60 \mu \mathrm{s}$.

In Figure 7, these shell-like cracks on the cross section of $\mathrm{B}-\mathrm{B}^{\prime}$ are initiated at the lateral part of the initial flaw at time $t=40 \mu$ s when the wing cracks had propagated a certain distance, and the initial propagation direction was along the dynamic loading direction while the wing cracks (antiwing cracks) had already altered their propagation direction to the side boundaries at time $t=40 \mu \mathrm{s}$. When these horizontal tensile cracks appeared on the surface of the specimen around time $t=45 \mu \mathrm{s}$, these horizontal tensile cracks emerged inside the specimen in the same manner, which were also perpendicular to the dynamic loading direction. These horizontal tensile cracks initiated inside the specimen 


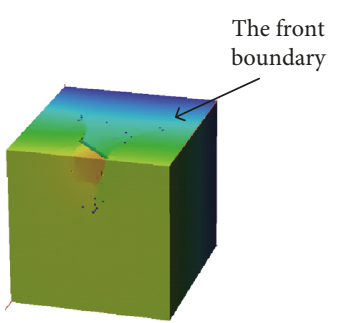

(a)

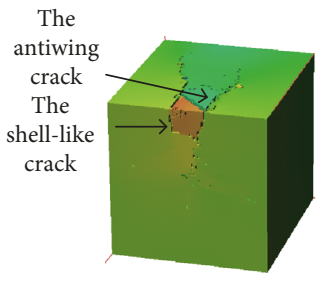

(c)

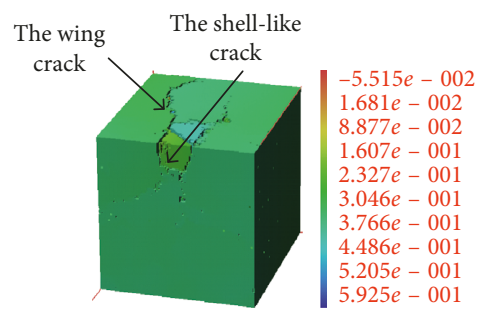

(e)

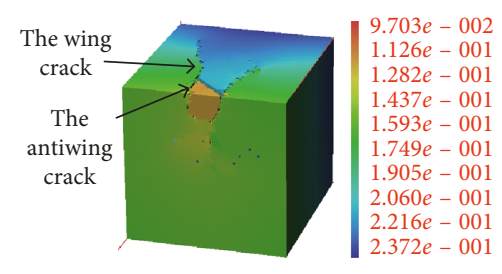

(b)

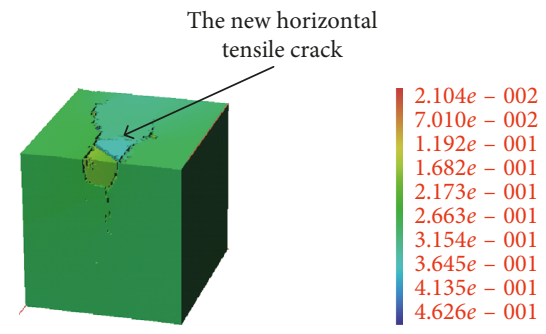

(d)

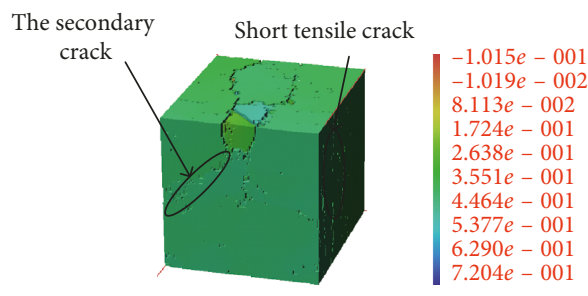

(f)

FIGURE 8: Plot of propagation of shell-like crack inside of the rock specimen that contains the flaw of $45^{\circ}$ at different select time on section A-A': (a) $t=30 \mu \mathrm{s}$, (b) $t=35 \mu \mathrm{s}$, (c) $t=40 \mu \mathrm{s}$, (d) $t=45 \mu \mathrm{s}$, (e) $t=50 \mu \mathrm{s}$, and (f) $t=60 \mu \mathrm{s}$.

propagated and coalesced to the horizontal tensile cracks that appeared on the surface around at time $t=50 \mu \mathrm{s}$, as shown in Figure 7(b). These new horizontal tensile cracks were generated by the stress reflecting in the area which consisted of the wing cracks, shell-like cracks, and the preexisting flaw, which were perpendicular to the loading direction.

Besides, these shell-like cracks never propagated to the top or bottom boundaries and stopped extending when they attached the wing cracks (or antiwing cracks). However, the wing crack (or antiwing cracks) could reach the top or bottom boundary, as shown in Figures 7(e)-7(f). Based on our numerical results, the shell-like cracks are a unique type of crack in the 3D state and cannot be regarded as extensions of wing crack.

Figure 8 depicts the propagation process of cracks along the slice $\mathrm{A}-\mathrm{A}^{\prime}$. When the wing cracks had already initiated and propagated at time $t=30 \mu \mathrm{s}$, the shell-like cracks began to grow at this time along the inside contour of the surface flaw. With the incident compressive stress wave propagation, the wing cracks and shell-like cracks continued to grow, and the antiwing cracks appeared on the surface of the specimen at time $t=40 \mu \mathrm{s}$ (Figure $8(\mathrm{c})$ ). Due to the coalescence of the antiwing cracks and the shell-like cracks, a semiellipse on the cross section of $\mathrm{A}-\mathrm{A}^{\prime}$ was seen at this time, as shown in Figure 8. A new type of inside crack was observed, initiating at the shell-like cracks contour line at time $t=45 \mu \mathrm{s}$ when the wing cracks stop propagating. And then, they propagated toward the specimen's back boundary in a certain distance with no branching. However, at $t=50 \mu \mathrm{s}$, this new type of inside cracks emerged crack branching and propagated toward the two sides and back boundaries of the specimen, as shown in Figure 8(e). The intersection of the secondary cracks and the boundary was in the middle place at $t=60 \mu \mathrm{s}$. The AE counts distribution could also obviously present these cracks, which are mainly in the tensile failure mode, as shown in Figure 4(f). One possible reason to account for this is that the applied stress wave was reflected multiple times on the front, back, left, and right specimen boundaries and superimposed tensile waves in the middle area prompting these new types of inside cracks to the corresponding boundary.

\subsubsection{The AE Energy Characteristics under Dynamic Loading.} To examine the AE characteristics of the specimen containing a single flaw under dynamic loading, the history of the released cumulative $\mathrm{AE}$ energy and $\mathrm{AE}$ events was recorded as shown in Figure 9.

At the beginning of the dynamic compressive loading, the value of stress wave was initially muted. Only a small number of weak elements in numerical specimen occurred. Until the wing cracks appeared around the preexisting flaw, 


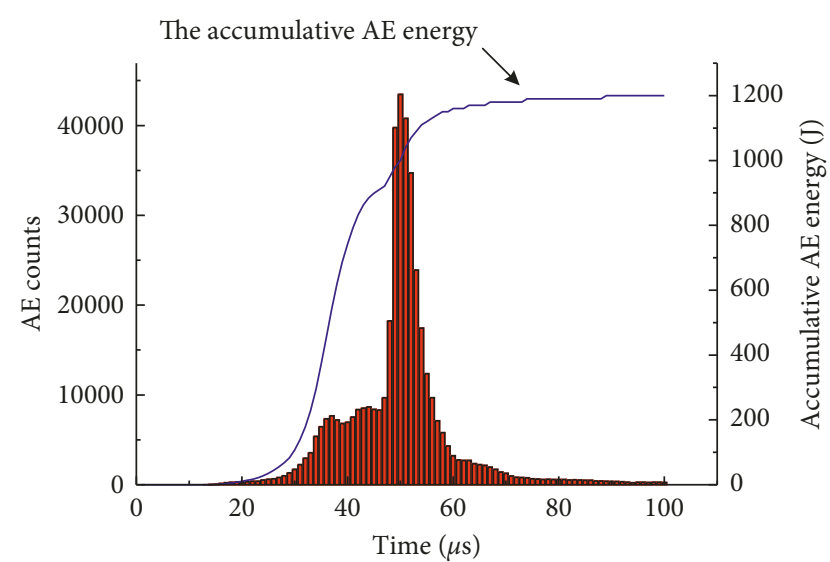

Figure 9: Numerical simulation of $\mathrm{AE}$ counts and $\mathrm{AE}$ energy versus time due to impact loading with single flaw.

AE event counts and AE energy gradually increased when $t$ was $30 \mu \mathrm{s}$. However, in the stage of before crack initiation, the amount of $\mathrm{AE}$ counts and accumulative $\mathrm{AE}$ energy released are still low. With the incident waves applying (about $30 \mu \mathrm{s} \leq t \leq 45 \mu \mathrm{s}$ ), the specimen went to the crack initiation. Since different types of cracks initiated and propagated, the AE counts occur frequently and the cumulative AE energy was markedly increased. When the specimen entered the crack propagation stage (about $45 \mu \mathrm{s} \leq t \leq 60 \mu \mathrm{s})$, the incident stress wave was completely applied and occurred the reflection inside the specimen. The specimen is significantly increasing of AE counts and released energy in this stage. This may be caused by the propagation of inside crack and appearance of the large number of tensile cracks, as shown in Figure 7(f). When the loading time was greater than $60 \mu \mathrm{s}$, the specimen was in the failure stage and a large number of tensile cracks emerged. The number of AE counts dropped rapidly, and the accumulative AE energy released increased slowly. Thus, the failure of the specimen under dynamic loading could be predicted by the sharp increase in the number of AE counts and the accumulative AE energy released significantly increased.

4.2. Effect of the Amplitude of the Incident Pressure on Dynamic Failure Process. Figure 10 depicts the failure processes of rock samples for different amplitudes of the incident wave, i.e., the testing nos. 1, 2, 3, and so on in Table 1 . When $t \leq 20 \mu \mathrm{s}$, there was no difference for the preexisting flaw specimens subjected to different dynamic loadings. In this phase, the specimen underwent an elastic deformation, and very few microfractures $\mathrm{AE}$ events were observed throughout the entire specimen. When $t$ is equal to $30 \mu \mathrm{s}$, the wing cracks appeared at two tips of the flaw in all three different impact loading cases and the antiwing cracks also formed at the surface of the specimens. For the condition $P$ equal to $50 \mathrm{MPa}$, only some damaged elements occurred around the preexisting flaw, and stress concentration was observed around the edge of the flaw as shown in Figure 10(a), especially the two tips of the flaw. When $P=60 \mathrm{MPa}$, more damage elements occurred at two flaw tips and the wing cracks appeared. However, for the condition $P$ equal to $70 \mathrm{MPa}$, more damaged elements occurred around the preexisting flaw than in the case of $P=60 \mathrm{MPa}$.

When time was $50 \mu \mathrm{s}$, the wing cracks and antiwing cracks propagated on the surface of the specimen, and the propagation length increased with the peak value.

With a higher $P$ condition, it was obvious that the upwing cracks on the surface of the specimen propagated to the specimen top in a shorter time. For example, the antiwing cracks in the case of $P=70 \mathrm{MPa}$ propagated upward to the top of the specimen and the wing cracks with no crack branching at time $t=60 \mu \mathrm{s}$. However, the antiwing cracks only propagated a certain distance for the condition $P$ equal to $50 \mathrm{MPa}$. Meanwhile, more cracks were formed on the surface of the specimen with a higher condition of $P$ value, and these phenomena also appeared inside the specimen such as the shell-like cracks, as shown in Figures $10(\mathrm{~d})-10\left(\mathrm{~d}^{\prime \prime}\right)$. In the failure mode stage, it could be seen that the test with a lower amplitude value produced few fragments among those three conditions. In other words, the area of fragmentation increased with increasing stress wave amplitude, which agrees with the findings in laboratory [36]. The main reason for this phenomenon is that the bigger the peak value, the more the energy the incident wave carries, regardless of the degree of fragmentation and crack propagation.

Figure 11 presents the $\mathrm{AE}$ counts and the accumulated AE energy versus time for three different incident waves. It is found that the accumulated AE counts increased with increasing stress wave amplitude. From Figure 11, it can be observed that the shapes of the AE count curve for different stress wave amplitudes are generally similar. The occurrence of $\mathrm{AE}$ counts concentrated on the loading period ranges from $30 \mu$ s to $70 \mu \mathrm{s}$, which could be divided into two sections. When the loading time increased from $30 \mu \mathrm{s}$ to $50 \mu \mathrm{s}$, the crack initiated and propagated around the preexisting flaw on the surface of the specimen, and during the next period ( $50 \mu \mathrm{s} \leq t \leq 70 \mu \mathrm{s})$ a large peak appeared due to propagation of the cracks inside the specimen including the spalling cracks across the specimen, which are mainly caused by the reflected stress waves. Figure 12 presents the relationship between applied stress wave amplitude and the derived accumulated AE counts. The AE counts were greatest for the case of $P=70 \mathrm{MPa}$. The time of the AE counts peak appeared earlier with increasing amplitude values, and the accumulative AE counts followed the same law which appeared greater with increasing amplitude values. The main reason for this phenomenon is that the bigger the peak value condition, the more the energy the incident wave carries. The specimen has more energy for crack propagation and AE events.

\subsection{Effect of the Cutting Depth of Flaw on Dynamic Failure} Process. Since crack propagation process was analyzed before when stress wave I was applied, the failure process analysis was concentrated on cases 6 and 7. Only the significant difference in crack propagation and $\mathrm{AE}$ 


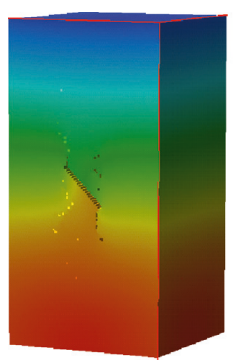

(a)

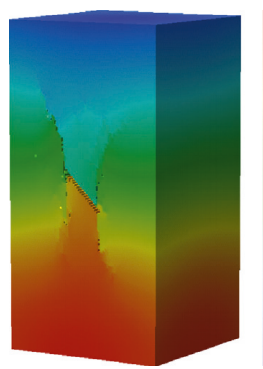

$\left(a^{\prime}\right)$

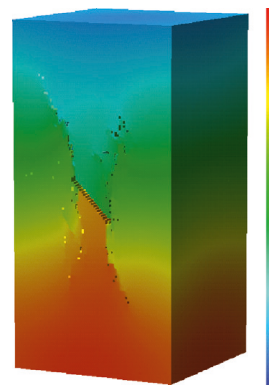

$\left(a^{\prime \prime}\right)$

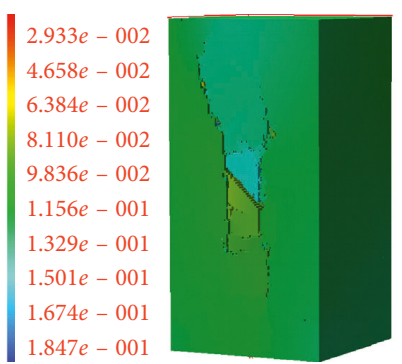

(b)

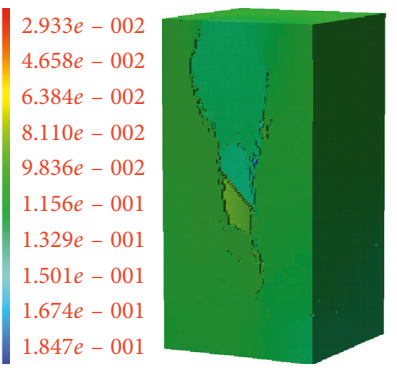

$\left(b^{\prime}\right)$

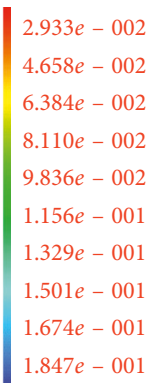

001

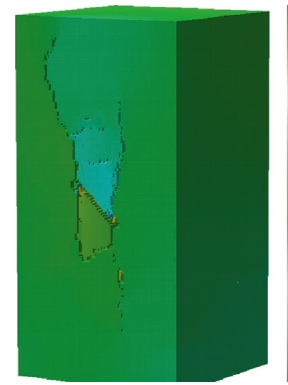

$\left(b^{\prime \prime}\right)$

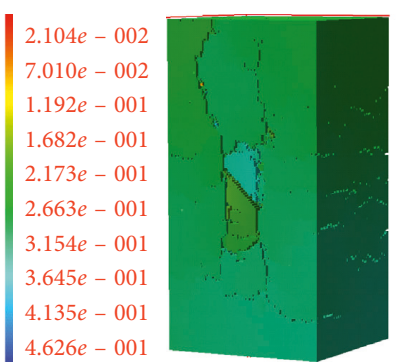

(c)
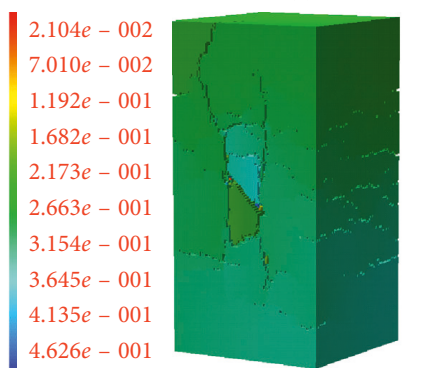

$\left(c^{\prime}\right)$
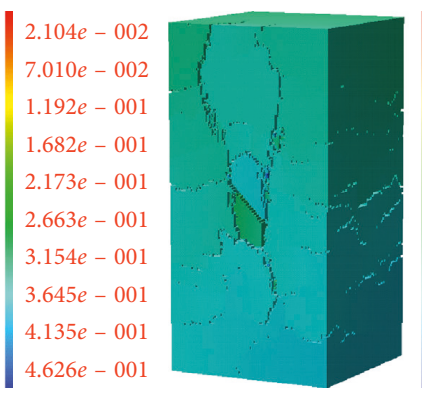

$\left(c^{\prime \prime}\right)$

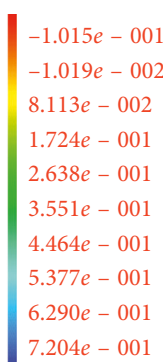
$-1.015 e-00$
$-1.019 e-002$
$8.113 e-002$
$1.724 e-001$
$2.638 e-001$
$3.551 e-001$
$4.464 e-001$
$5.377 e-001$
$6.290 e-001$
$7.204 e-001$ $7.204 e-001$

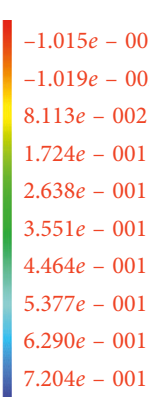

$6.290 e-001$

FIgURE 10: Numerical simulation of the effect of three kinds of compressive stress waves on the failure process of specimens. The first row $(\mathrm{a}-\mathrm{d})$ is the maximum value of $50 \mathrm{MPa}$, the second row $\left(\mathrm{a}^{\prime}-\mathrm{d}^{\prime}\right)$ is the maximum value of $60 \mathrm{MPa}$, and the third row $\left(\mathrm{a}^{\prime \prime}-\mathrm{d}^{\prime \prime}\right)$ is the maximum value of $70 \mathrm{MPa}$.

characteristic for different flaw depths was investigated. The $x$-axial displacement distribution, as well as cracking sequence from initiation to final failure, for different flaw depths under stress wave I was shown in Figures 13 and 14. When $t$ was $30 \mu \mathrm{s}$, for case 6 , the initiation of wing cracks and shell-like cracks was the same as described above. However, for case 8 , the wing cracks had already initiated and propagated a certain distance at this time. Meanwhile, there were no shell-like cracks initiated inside the specimen. When $t$ was $40 \mu \mathrm{s}$, the antiwing cracks and the shell-like cracks initiated and propagated in case 6 . But, for case 7 , only the left tip of the flaw initiated the antiwing crack on the surface. And many short cracks initiated and formed a crack band that was parallel to the preexisting flaw at a distance above the flaw. When $t$ was $60 \mu \mathrm{s}$, for case 6 , the antiwing cracks propagated to the top of the specimen that was different from that of case 1 . There also appeared a new type of cracks, which were perpendicular to the loading direction, connected shell-like cracks, and antiwing cracks. For case 7 , no shell-like cracks and new type of cracks as mentioned above appeared inside the specimen. Comparing three different flaw depths, it is only a deeper flaw that initiated more cracks and had a faster crack propagation process leading to a more effective fragmentation. These phenomena indicated that the flaw depth is not only closely related to the crack propagation behavior and failure mode but it also affects the fragmentation of rock.

Figure 15 illustrates the physical test results of the rocklike specimen with the flaw cut through the entire specimen under the dynamic loading test conducted by Zou et al. (2015). As can be seen from the experimental results, a series of cracks composing a " $\mathrm{X}$ " shape crack band lead to the macroscopic failure. Numerical simulations in this article have shown that the simulated crack propagation process and failure mode are highly consistent with the physical experiment conducted by Zou.

Figure 16 presents numerical simulations of AE counts and the accumulative AE energy released versus time for different cutting depths of the flaw (Figure 17). Figure 18 describes the accumulative AE count with different cutting depths of the flaw. It is indicated that the characteristic of AE counts and cumulative energy have a difference with different flaw depths. For case 7, the AE counts increased to the peak dramatically when $t=35 \mu \mathrm{s}$ and then gradually 


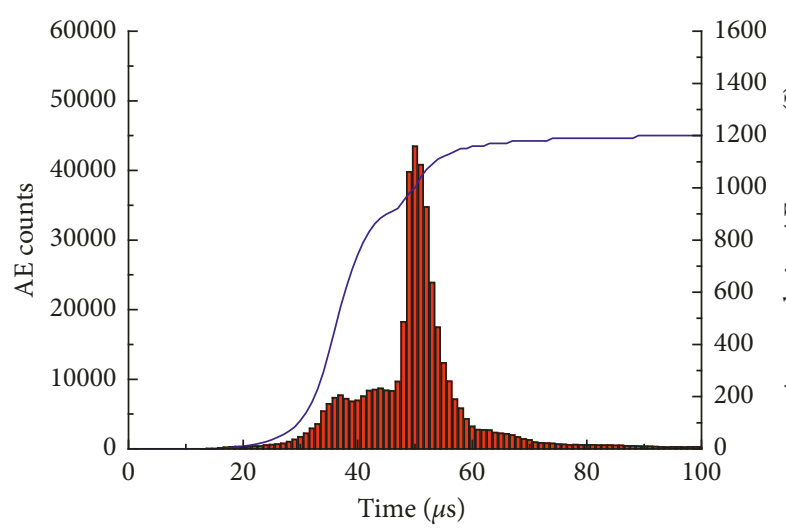

(a)

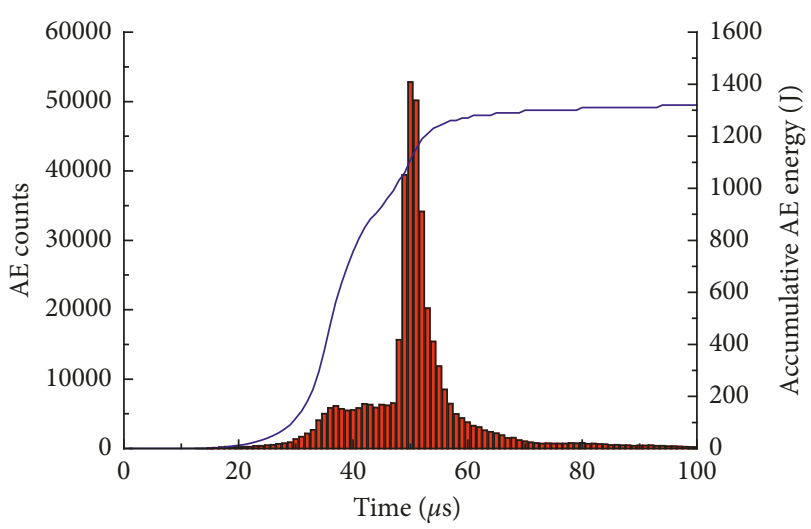

(b)

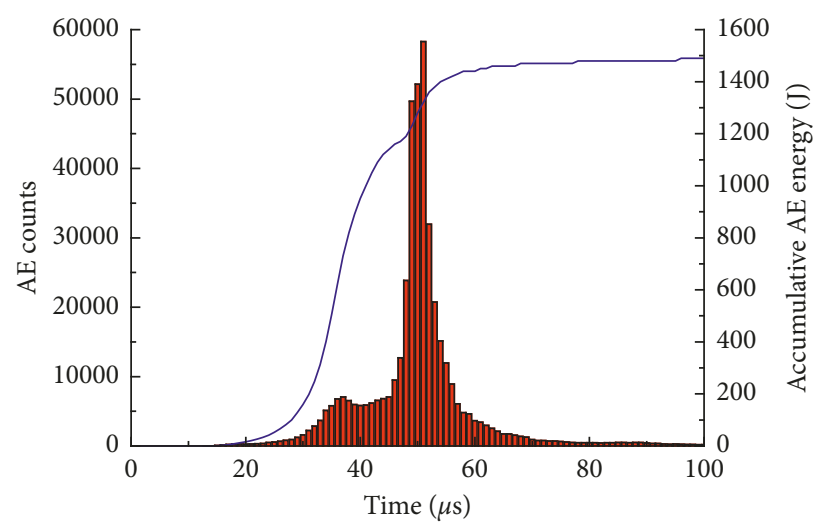

(c)

FIGURE 11: Numerical simulation of AE counts and accumulative AE energy versus time due to impact with the maximum pressures of (a) $50 \mathrm{MPa}$, (b) $60 \mathrm{MPa}$, and (c) $70 \mathrm{MPa}$.

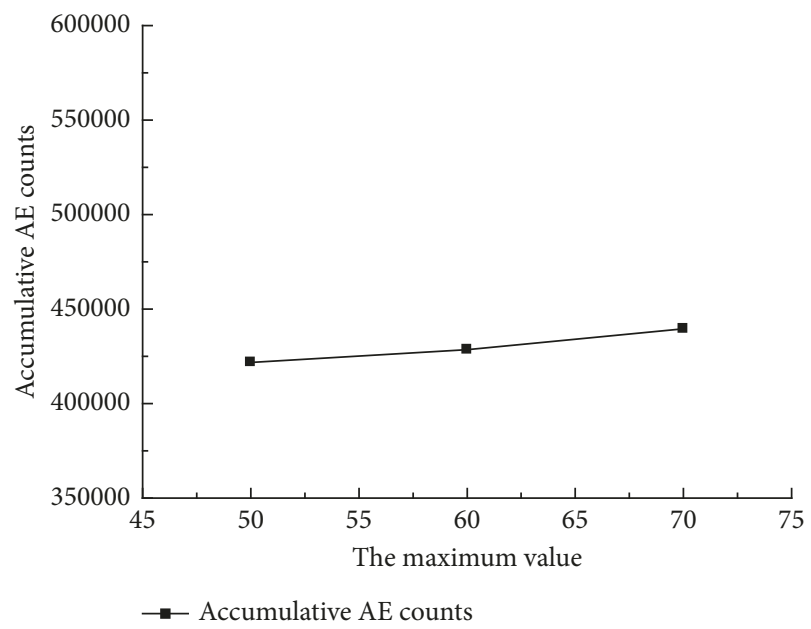

FIGURE 12: Numerical simulation of the accumulative AE counts due to impact loading with different maximum pressures.

decreased until $t$ was $60 \mu$ s. And, AE counts increased dramatically at about $t=30 \mu \mathrm{s}$ and increased to the peak at $t=45 \mu \mathrm{s}$ in case 6 . These phenomena illustrate that the time of $\mathrm{AE}$ counts peak and the distribution of $\mathrm{AE}$ counts are closely related to the depth of the flaw. Meanwhile, with increasing cutting depth of the flaw, the accumulative AE energy released and AE counts increased obviously.

The most likely to account for these phenomena are that as flaw depth increased, more stress waves reflected at the preexisting flaw and the reflected waves then superposed. With the cutting depth of flaw increasing, the more stress waves are blocked and reflected by the preexisting flaw, the more stress waves are superposed, which generate more $\mathrm{AE}$ events, energy, and cracks.

\section{Numerical Simulation on Dynamic Fracture of Rocks with Surface Multiflaws}

As mentioned above, the dynamic impact loading had a great influence on the crack initiation and propagation of the specimen with a single flaw. However, for specimens containing multiflaws, the coalescence of preexisting flaws played a decisive role on the mechanical properties of the rock mass. The real-time crack coalescence behavior of the specimens containing multiflaws was analyzed, as shown in Figures 18 and 19, and the definition of the flaws I and II in model $b$ and I and III in model $c$ had been described in Figures 2(b) and 2(c). The key research results were described as follows. 


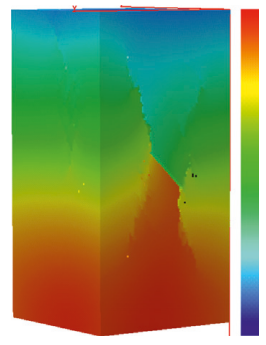

(a)

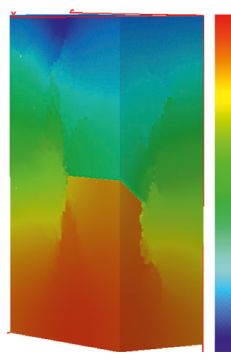

$\left(a^{\prime}\right)$

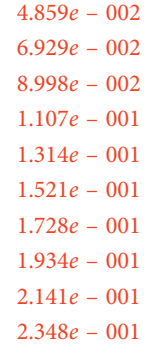

$4.883 e-002$

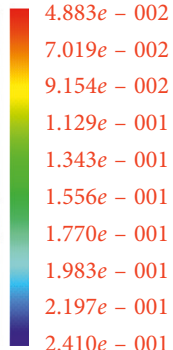

$2.410 e-001$

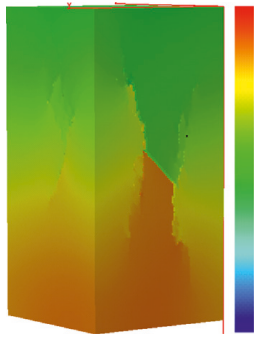

(b)

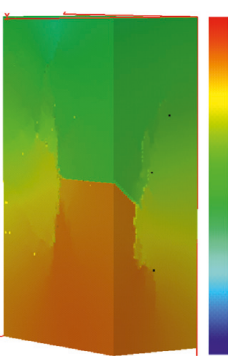

$\left(\mathrm{b}^{\prime}\right)$
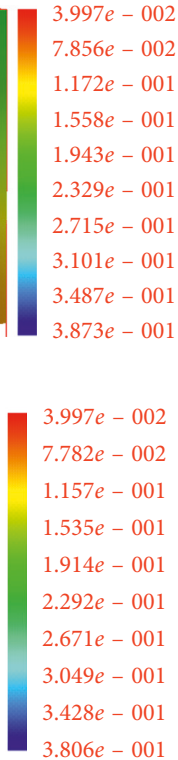

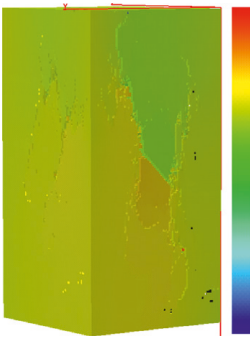

(c)

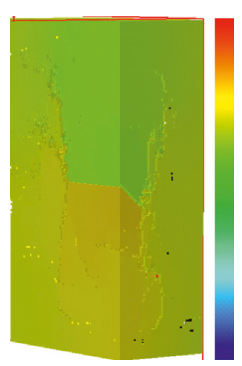

$\left(c^{\prime}\right)$

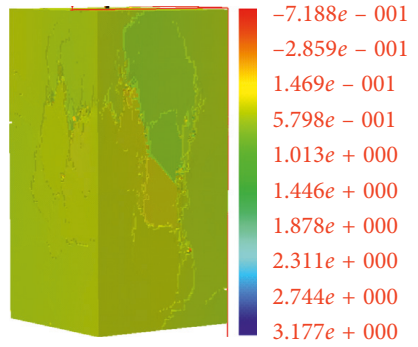

(d)

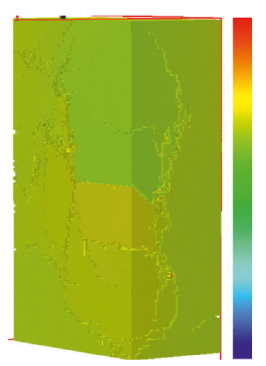

$-7.188 e-001$ $-2.859 e-001$ $1.469 e-001$ $5.798 e-001$ $1.013 e+000$ $1.446 e+000$ $1.878 e+000$ $2.311 e+000$ $2.744 e+000$

$\left(d^{\prime}\right)$

FIgURE 13: The crack propagation on the surface of and inside the specimen with flaw depth $b=20 \mathrm{~mm}$ at select time. The first row (a-d) is for the crack propagation on the surface of the specimen, and the second row $\left(\mathrm{a}^{\prime}-\mathrm{d}^{\prime}\right)$ is for crack propagation inside the specimen (plan section $B-B^{\prime}$ in Figure 3(a)).

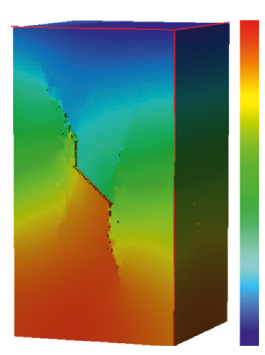

(a)

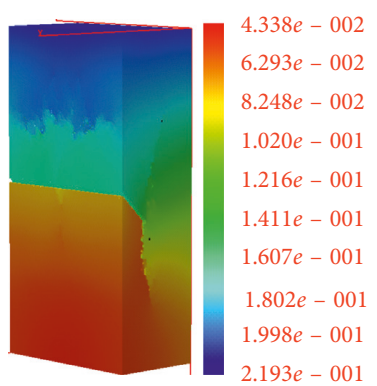

$\left(a^{\prime}\right)$

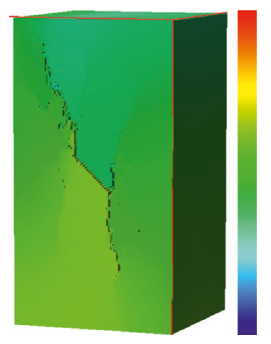

(b)

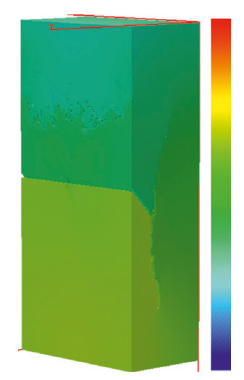

(b')
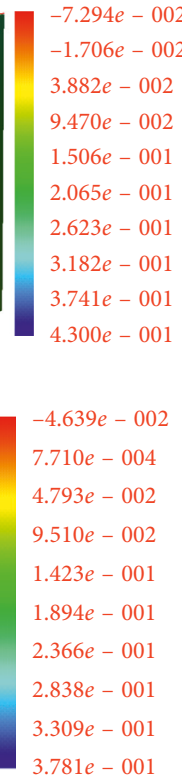

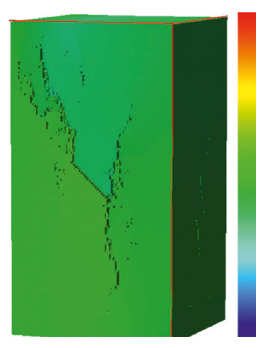

(c)

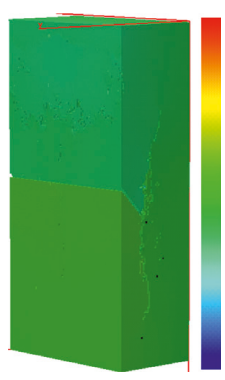

(c')

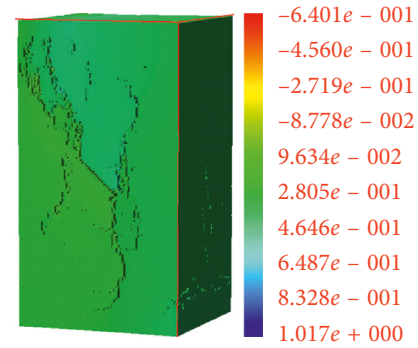

(d)

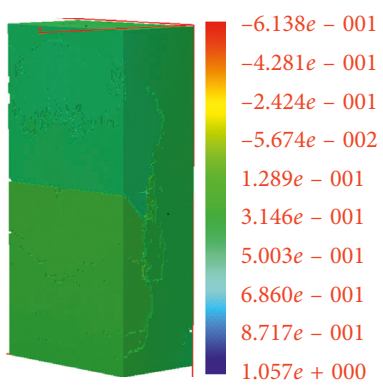

(d')

Figure 14: The crack propagation on the surface of and inside the specimen with flaw depth $b=20 \mathrm{~mm}$ at select time. The first row (a-d) is for the crack propagation on the surface of the specimen, and the second row $\left(a^{\prime}-\mathrm{d}^{\prime}\right)$ is for crack propagation inside the specimen (plan section B-B' in Figure 3(a)).

For model b, the wing crack initiated at the left tip of the second flaw (II) at $t=35 \mu$ s and coalesced to the same side tip of the first flaw (I) at $t=40 \mu \mathrm{s}$. Before time $t=45 \mu \mathrm{s}$, no wing crack was observed in the bottom right tips of the first flaw (I). However, the coalescence path was from the right tip of the first flaw (I) to the center of adjacent second flaw (II) at $t=50 \mu \mathrm{s}$. Around time $t=45 \mu \mathrm{s}$, the antiwing crack propagated to both the top and bottom of the specimen, which initiated and propagated to a certain distance from the first flaw (I). For the left tips of flaw, the antiwing cracks coalesced on the wing crack that referred to the linkage of the two preexisting flaws.

For model c, there has been a more complicated, crack coalescence behavior. Coalescence referred to the linkage of the left of two flaws' tips (I and II) by a wing crack trajectory that initiated the second preset flaw (II) at $t=45 \mu \mathrm{s}$. 


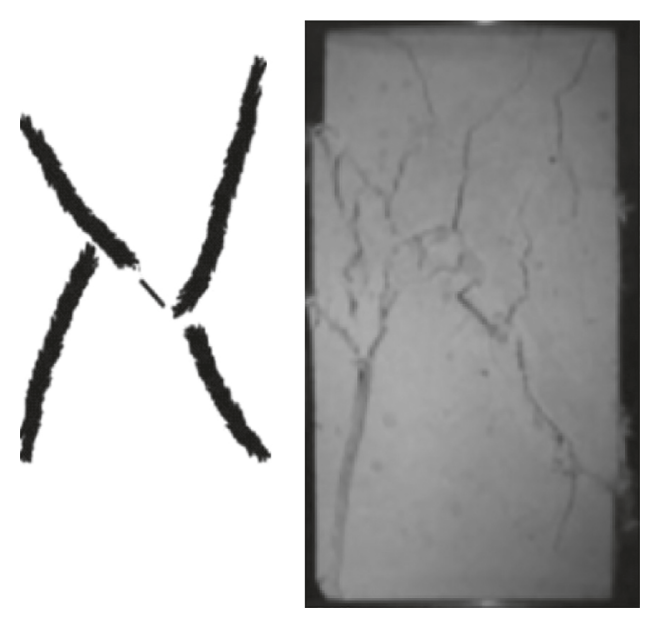

(a)

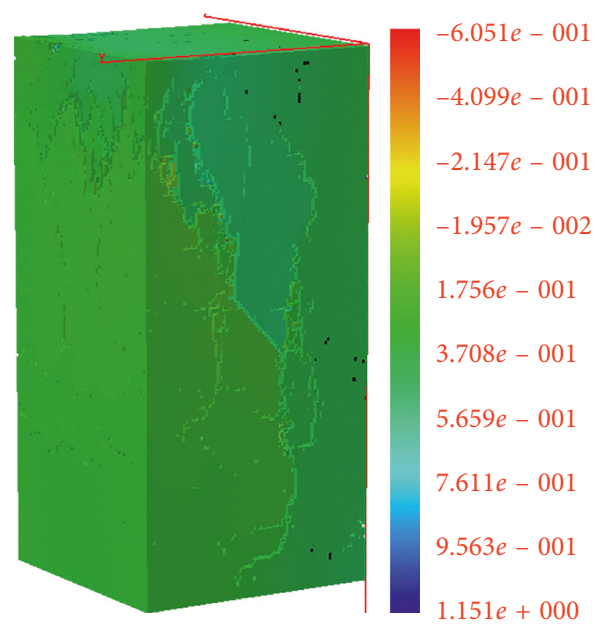

(b)

Figure 15: The fracture process for (a) the physical experiment conducted by Zou and (b) the final fracture patterns for numerical simulation.

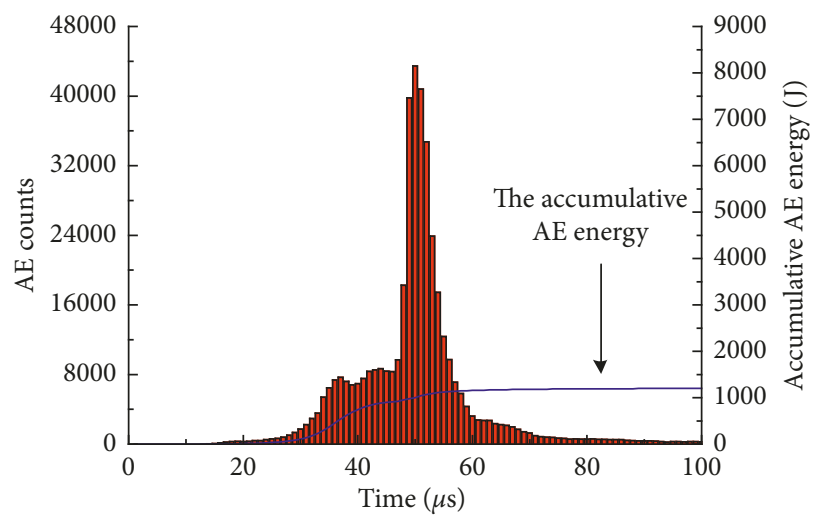

(a)

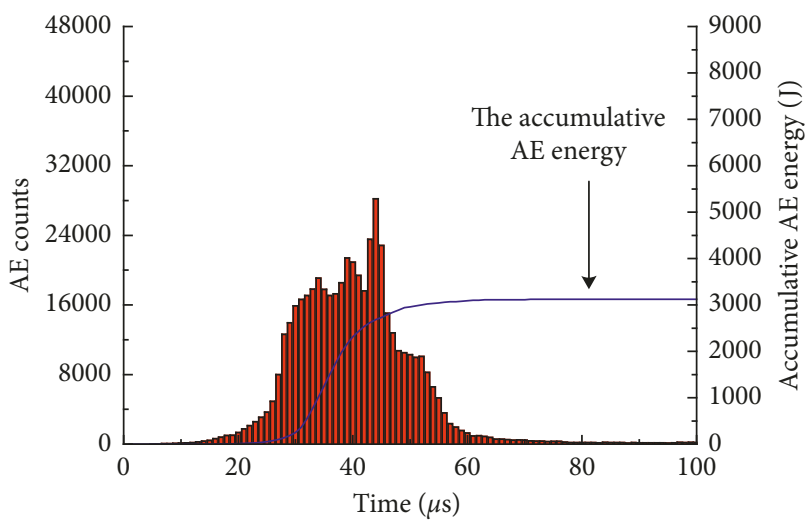

(b)

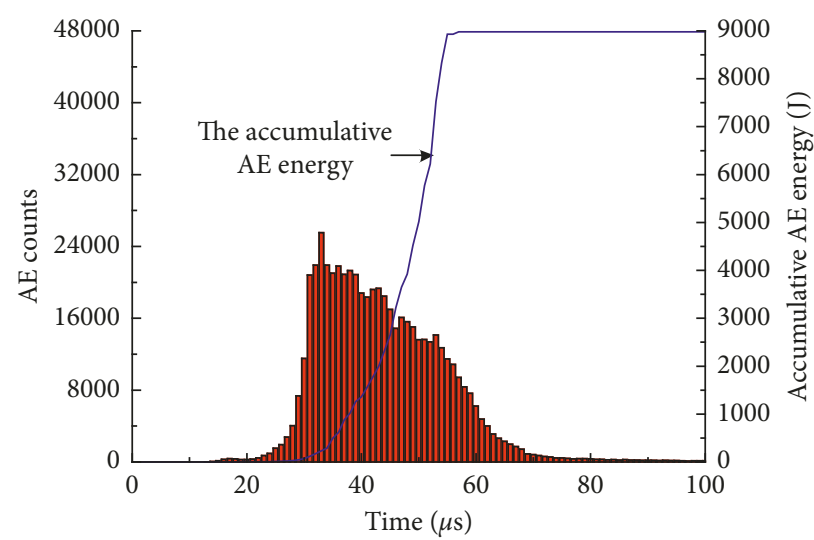

(c)

FIGURE 16: Numerical simulation of AE counts and accumulative AE energy versus time due to impact with the flaw depth of (a) 6 mm, (b) $20 \mathrm{~mm}$, and (c) $40 \mathrm{~mm}$.

And when $t$ was $60 \mu \mathrm{s}$, the linkage of two right flaws' tips (I and II) by a wing crack trajectory was initiated at the first flaw (I). Unlike model b, there occurred another crack coalescence. The coalescence points are relatively far away from the dotted reference line. The antiwing cracks that initiated at the left of the third flaw (III) coalesced to the wing cracks that linked two flaws (I and II) at $t=50 \mu$ s. After the coalescence, these two cracks continued to propagate as 


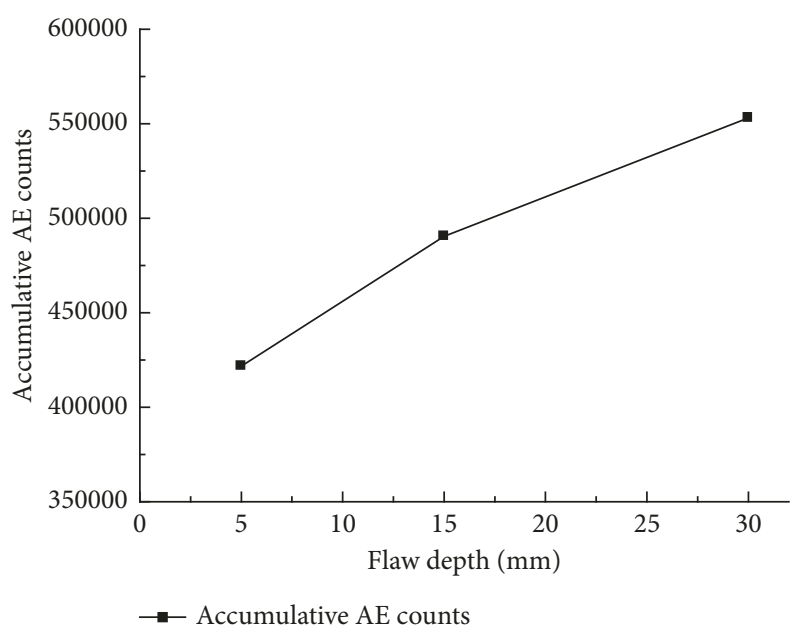

FIGURE 17: Numerical simulation of the accumulative AE counts due to impact loading with different flaw depths.

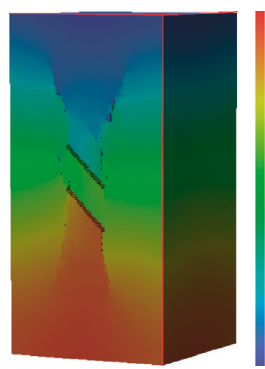

(a)

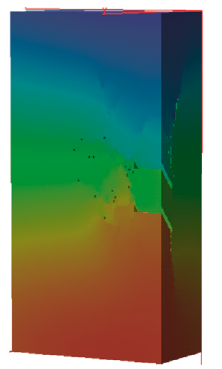

$\left(a^{\prime}\right)$
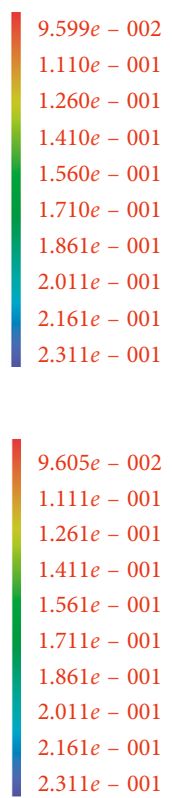

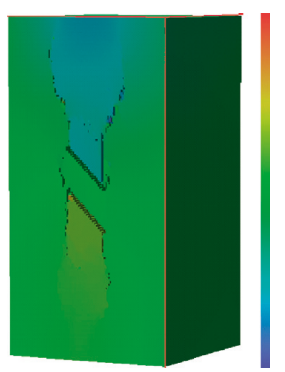

(b)

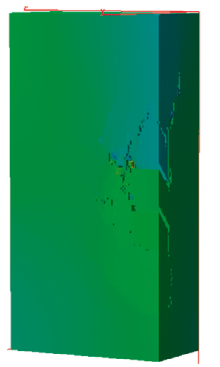

$\left(\mathrm{b}^{\prime}\right)$

()

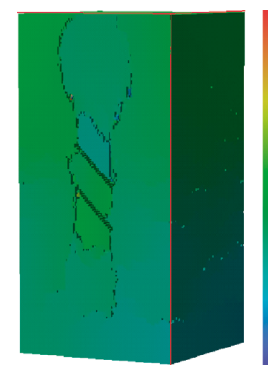

(c)
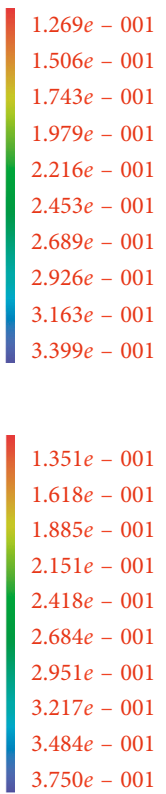

$1.351 e-001$
$1.618 e-001$
$1.885 e-001$
$2.151 e-001$
$2.418 e-001$
$2.684 e-001$
$2.951 e-001$
$3.217 e-001$
$3.484 e-001$
$3.750 e-001$

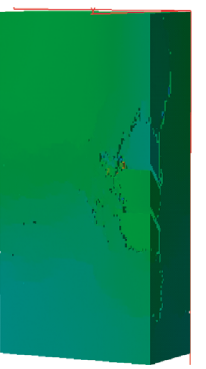

$\left(c^{\prime}\right)$

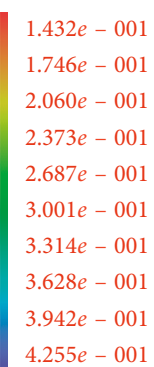

(c)

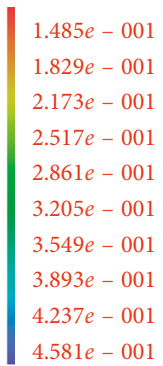

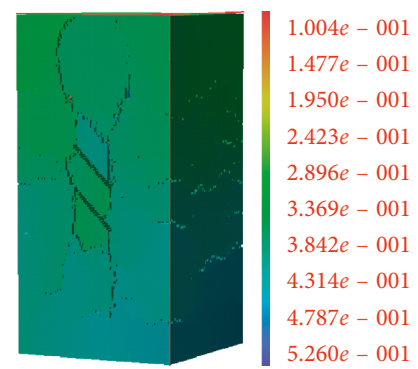

(d)

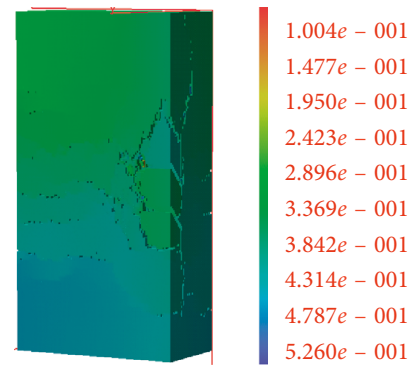

$\left(\mathrm{d}^{\prime}\right)$

Figure 18: The crack propagation on the surface of and inside the specimen with two parallel flaws at select time. The first row (a-d) is for the crack propagation on the surface of the specimen and the second row $\left(\mathrm{a}^{\prime}-\mathrm{d}^{\prime}\right)$ is for the crack propagation inside the specimen (plan section $B-B^{\prime}$ in Figure 3(a)).

one crack trajectory. For the process of coalescence with three preexisting flaws, not all the preexisting flaw tips appeared as wing cracks or antiwing cracks. There were no cracks that were observed in the right tips of two flaws (II and III).

Figure 20 shows the plots of AE counts and accumulative AE energy released for the specimen with the multiflaws. As the numerical simulation results depict, the trend of $\mathrm{AE}$ counts in time distribution and the cumulative AE energy released are basically similar. For example, majorities of AE counts were found after time $t=20 \mu \mathrm{s}$, and it remained stable until time $t=80 \mu \mathrm{s}$. The AE counts peak emerged in these three cases was all at about $t=50 \mu \mathrm{s}$, when the stress wave was nearly applied. However, the accumulative AE energy increased as the number of cracks increased in this study. Figure 21 presents the numerical simulation of accumulative AE counts with multiflaws. The accumulative AE counts curve shows a concave phenomenon and slows growth with the addition of flaw number. The coalescence behavior and $\mathrm{AE}$ events in rocks mainly depend on the stress distribution. The influence of multiflaws of the specimen on the failure process can be explained by the fact that the reflection and superposition of the stress waves of the specimen is more frequent and complicated with the increase in the number of flaws. The coalescence behavior with three preexisting flaws is more completely different than that with the two preexisting flaws case. The coalescence between flaw tips is not easy to achieve under more preexisting flaws model. 


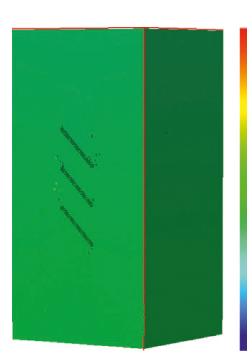

(a)

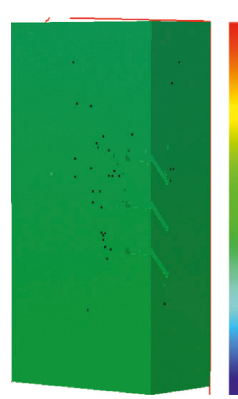

$\left(a^{\prime}\right)$
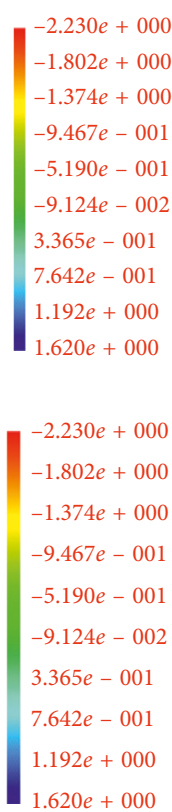

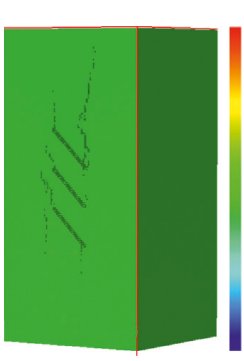

(b)
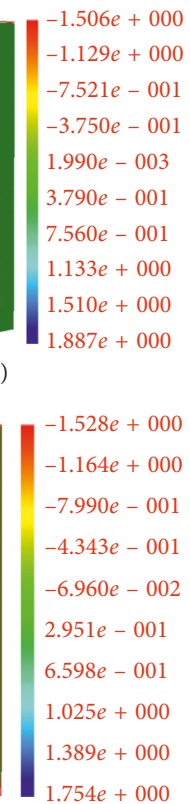

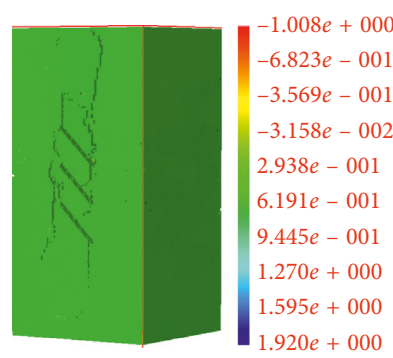

(c)

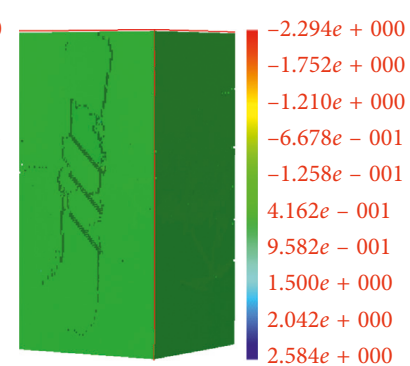

(d) $\left(\mathrm{b}^{\prime}\right)$

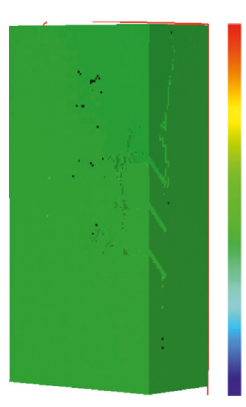

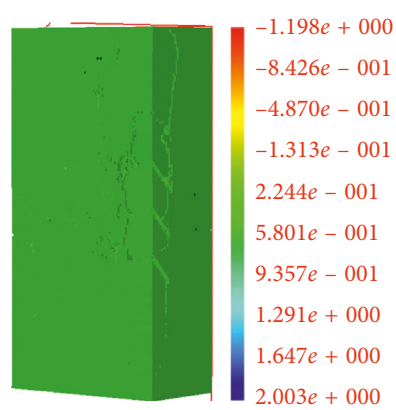

$\left(c^{\prime}\right)$

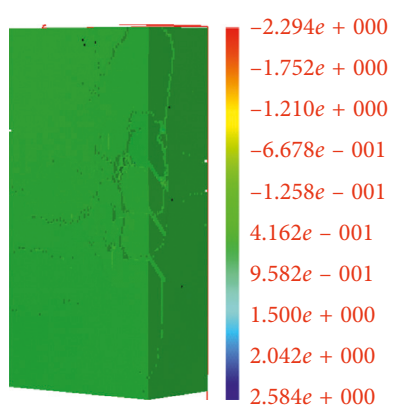

$\left(d^{\prime}\right)$

FIGURE 19: The crack propagation on the surface of and inside the specimen with three parallel flaws at select time. The first row (a-d) is for the crack propagation on the surface of the specimen, and the second row $\left(a^{\prime}-d^{\prime}\right)$ is for the crack propagation inside the specimen (plan section $B-B^{\prime}$ in Figure 3(a)).

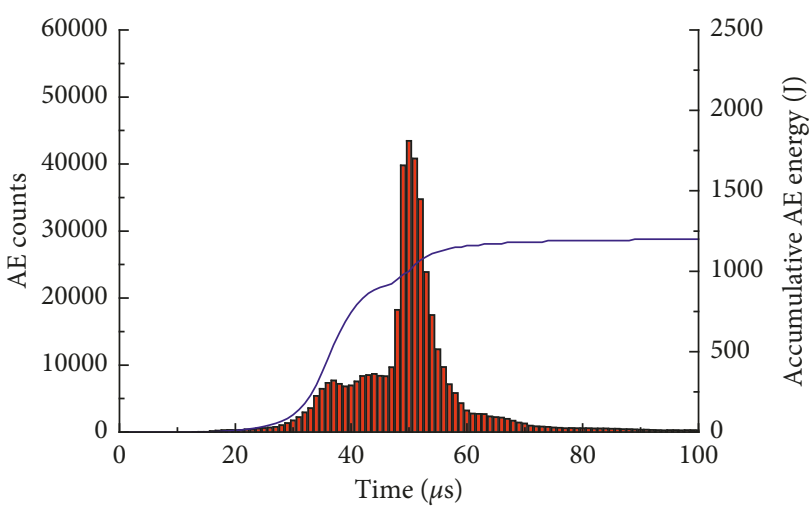

(a)

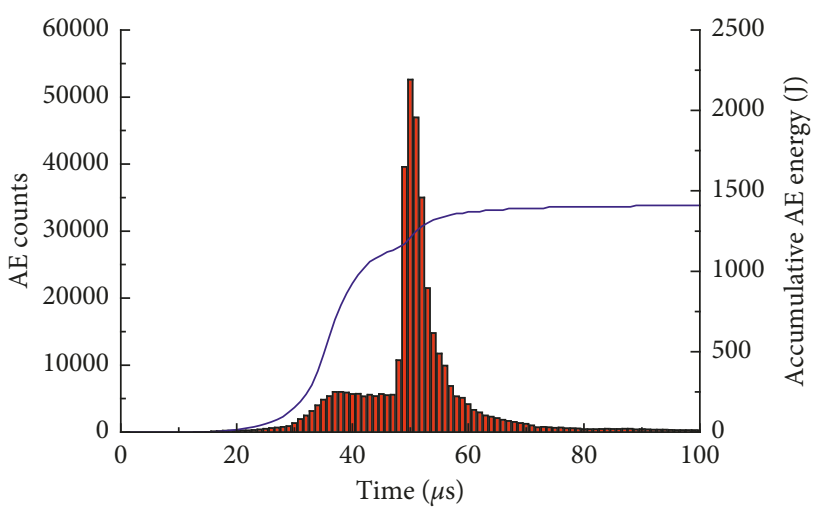

(b)

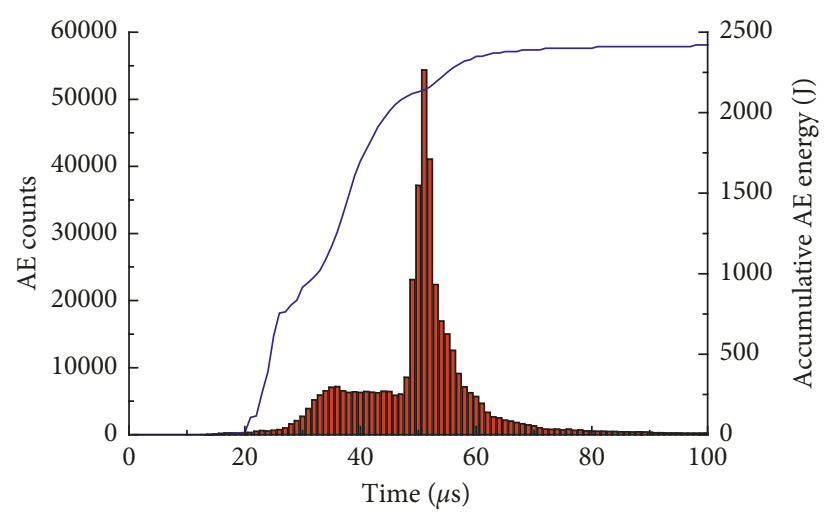

(c)

Figure 20: Numerical simulation of AE counts and accumulative AE energy versus time due to impact with the multiflaws. The specimen with (a) single flaw, (b) two parallel flaws, and (c) three parallel flaws. 


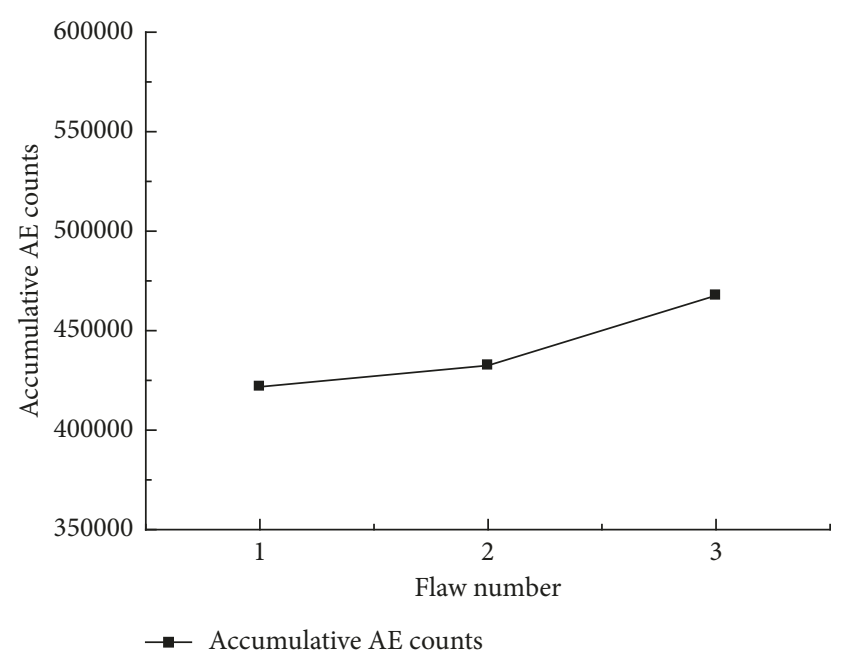

FIgURE 21: Numerical simulation of the accumulative AE counts due to impact loading with different flaw numbers.

\section{Discussion}

6.1. Comparison with Static Results. Static compression tests for rock specimens with a preexisting surface flaw in three dimensional were conducted by $\mathrm{Wu}$ [37]. Figure 22 shows the numerical and experimental results of the previous study, which presents the failure mode of the specimen with a preexisting surface flaw. Model size and cracking setting in the static experiment are the same as the dynamic numerical simulation in this paper. It can be seen from the cracking mode that static numerical simulation is different from the results of this research.

First, only all the antiwing cracks emerged in static simulation, but they cannot be propagated to the top or bottom of the specimen. Second, the tensile cracks are not appeared, which are perpendicular to the loading direction. In dynamic loading, the compressive stress wave would be transformed the tensile, when they reached the boundaries and the preexisting flaw. However, there is no such phenomenon under the static loading condition. Third, the crack propagation path of the specimens under static loading is smoother and straighter. For example, the antiwing cracks emerged on the surface of the specimen in these two loading conditions, but their propagated path was a straighter line and could not occur curling in the static loading condition. In addition, the cracks initiated around the flaw dominate the static failure of the specimen containing a single flaw. However, the failure of the specimen was due to a large number of horizontal tensile cracks under the dynamic loading condition. These data indicate that the failure modes of the specimen with a single flaw under different loading conditions are significantly different. Under the dynamic loading condition, the macroscopic failure caused by a larger amount of short tensile cracks and more smaller size fragments is produced.

6.2. Different Crack Propagation Velocities between Cracks on the Surface of and inside the Specimen. Figure 23 depicts the

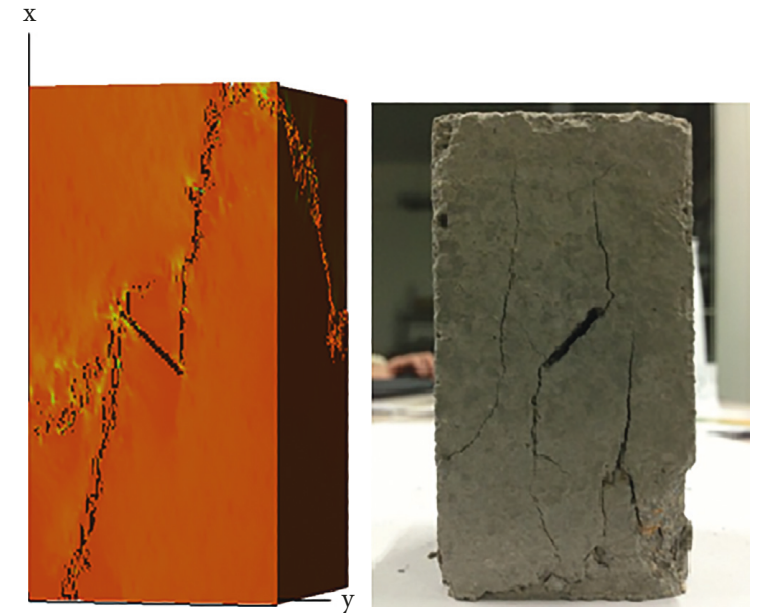

Figure 22: The results of the rock specimen containing a preexisting flaw with an dip angle of $45^{\circ}$ under the static loading condition.

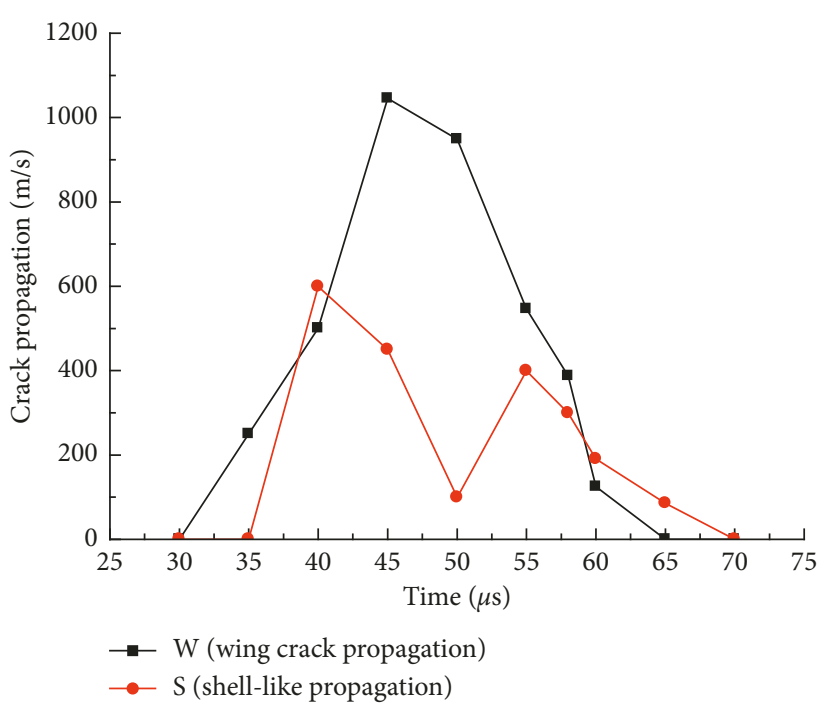

FIgURE 23: Crack tip propagation velocity for the wing crack propagation and the shell-like crack propagation.

crack propagation velocity versus time curves, where $W$ represents the wing cracks that initiated at the right tip of the preexisting crack. And $S$ represents the shell crack that initiated at the inner edge of the flaw. These two types of cracks initiated at different times are described above. The wing cracks initiated at about $t=30 \mu$ s and the propagation velocity of the crack $W$ on the surface of the specimen rapidly raised and reached the respective peak around at $t=45 \mu$ s after initiation, in which, the maximum propagation velocity of the crack $W$ was $1045 \mathrm{~m} / \mathrm{s}$. After that, the propagation velocity of the crack $W$ reduced to $949 \mathrm{~m} / \mathrm{s}$ at time $t=50 \mu \mathrm{s}$ and then drastically declined to $125 \mathrm{~m} / \mathrm{s}$ when time $t=55 \mu \mathrm{s}$. When time $t=65 \mu \mathrm{s}$ after impact, the propagation velocity decreased to $0 \mathrm{~m} / \mathrm{s}$.

Around time $t=35 \mu \mathrm{s}$, the shell-like cracks initiated and the propagation velocity of the crack $S$ rapidly raised and reached the respective peak at $40 \mu$ s after the crack initiation, 
which reached $599 \mathrm{~m} / \mathrm{s}$. The propagation velocity of the crack $S$ was reduced to $100 \mathrm{~m} / \mathrm{s}$ after $50 \mu$ s since it reached the respective first peak. After that, it raised again and reached $399 \mathrm{~m} / \mathrm{s}$ around $t=55 \mu \mathrm{s}$. When $t=70 \mu \mathrm{s}$, the propagation velocity reduced to $0 \mathrm{~m} / \mathrm{s}$.

As presented in numerical results, the wing crack on the specimen surface initiated earlier than the shell-like cracks that initiated inside the specimen, and the crack $W$ propagation velocity was also far greater than the crack $S$. These phenomena may due to the stress wave dispersion effect inside the rock. During the propagation process, the propagation velocity may have a fluctuations. Crack propagation velocity inside the specimen is markedly different from that on the surface.

\section{Conclusion}

This paper carried out the numerical simulation of 3D crack initiation and propagation on dynamics rock fracturing test by RFPA ${ }^{3 \mathrm{D}}$ _Dynamic. The conclusions are summarized as follows:

(1) The crack initiation and propagation on the surface are apparently different from that inside the rock specimen. The wing cracks and antiwing cracks on the surface are initiated earlier and propagated longer than the shell-like cracks inside the rock specimen.

(2) The change rule of crack direction on the surface is also more complicated than that of inside. The velocity of wing cracks and antiwing cracks propagation is greater than that of shell-like cracks. So, shelllike cracks cannot be referred as wing cracks that initiated from the inner contour of the preexisting flaw.

(3) The deeper the crack depths, the more the number of cracks; the greater the impact force, the more cracks the rock sample produces, the more the acoustic emission energy is released, and the more severe the rock breaks.

(4) The coalescence between flaw tips is not easy, and the coalescence of preexisting flaws usually needs two or multiple cracks to achieve. The coalescence points occurred not only in the preexisting flaw but also in the trajectory of the wing cracks and antiwing cracks.

(5) Short tensile cracks are the dominant reason for specimen failure, and the degree of fragmentation is more serious under dynamic loading condition compared to the static loading condition. Only the antiwing cracks emerged on the surface specimen under static loading condition.

\section{Data Availability}

The data used to support the findings of this study are available from the corresponding author upon request.

\section{Conflicts of Interest}

The authors declare that they have no conflicts of interest.

\section{Acknowledgments}

The authors hereby sincerely thank the support of the National Natural Science Foundation of China (Grant Nos. 51779031 and 51878190).

\section{References}

[1] Y. Guo, R. H. C. Wong, W. Zhu, K. T. Chau, and S. Li, "Study on fracture pattern of open surface-flaw in gabbro," Chinese Journal of Rock Mechanics and Engineering, vol. 26, no. 3, pp. 525-531, 2007.

[2] Z. Z. Liang, L. I. Lian-Chong, S. B. Tang, and Y. B. Zhang, "3D numerical simulation of growth of surface crack of rock specimens," Chinese Journal of Geotechnical Engineering, vol. 33, no. 10, pp. 1615-1622, 2011.

[3] F. Dai, S. Huang, K. Xia, and Z. Tan, "Some fundamental issues in dynamic compression and tension tests of rocks using split Hopkinson pressure bar," Rock Mechanics and Rock Engineering, vol. 43, no. 6, pp. 657-666, 2010.

[4] D. Li, T. Cheng, T. Zhou, and X. Li, "Experimental study of the dynamic strength and fracturing characteristics of marble specimens with a single hole under impact loading," Yanshilixue Yu Gongcheng Xuebao/Chinese Journal of Rock Mechanics and Engineering, vol. 34, no. 2, pp. 249-260, 2015.

[5] Z. Zhang, Y. Chen, and A. Ghassemi, "Simulation of dynamic fracture in rock with discretized virtual internal bond," Revue Du Vin De France, Marie Claire, Paris, France, 2014.

[6] W. C. Zhu, Y. Bai, X. B. Li, and L. L. Niu, "Numerical simulation on rock failure under combined static and dynamic loading during SHPB tests," International Journal of Impact Engineering, vol. 49, no. 2, pp. 142-157, 2012.

[7] G. W. Ma and X. M. An, "Numerical simulation of blastinginduced rock fractures," International Journal of Rock Mechanics and Mining Sciences, vol. 45, no. 6, pp. 966-975, 2008.

[8] R. S. Yang, Z. W. Yue, J. C. Dong et al., "Dynamic caustics experiment of blasting crack propagation in discontinuous jointed material," Journal of China University of Mining and Technology, vol. 37, no. 4, pp. 467-472, 2008.

[9] X. P. Zhang and L. N. Y. Wong, "Loading rate effects on cracking behavior of flaw-contained specimens under uniaxial compression," International Journal of Fracture, vol. 180, no. 1, pp. 93-110, 2013.

[10] X. P. Zhou, Q. H. Qian, and H. Q. Yang, "Effect of loading rate on fracture characteristics of rock," Journal of Central South University, vol. 17, no. 1, pp. 150-155, 2010.

[11] K. Xia, M. H. B. Nasseri, B. Mohanty, F. Lu, R. Chen, and S. N. Luo, "Effects of microstructures on dynamic compression of barre granite," International Journal of Rock Mechanics and Mining Sciences, vol. 45, no. 6, pp. 879-887, 2008.

[12] Q. M. Li and H. Meng, "About the dynamic strength enhancement of concrete-like materials in a split hopkinson pressure bar test," International Journal of Solids and Structures, vol. 40, no. 2, pp. 343-360, 2003.

[13] M. D. Wei, F. Dai, N. W. Xu, J. F. Liu, and Y. Xu, "Experimental and numerical study on the cracked chevron notched 
semi-circular bend method for characterizing the mode I fracture toughness of rocks," Rock Mechanics and Rock Engineering, vol. 49, no. 5, pp. 1595-1609, 2016.

[14] S. Zhang, Y. Lu, X. Chen, X. Teng, S. Yu, S. Zhang et al., "Further investigation on the real rate effect of dynamic tensile strength for concrete-like materials," Latin American Journal of Solids and Structures, vol. 13, no. 1, pp. 201-223, 20156.

[15] Z. Y. Liao, Z. Z. Liang, C. A. Tang, and Y. F. Yang, "Numerical simulation of the influence of joints on rock fragmentation by drill bit under impact loading," Applied Mechanics and Materials, vol. 256-259, pp. 522-525, 2012.

[16] Z. Y. Liao, J. B. Zhu, K. W. Xia, and C. A. Tang, "Determination of dynamic compressive and tensile behavior of rocks from numerical tests of split hopkinson pressure and tension bars," Rock Mechanics and Rock Engineering, vol. 49, no. 10, pp. 3917-3934, 2016.

[17] Y. H. Huang, S. Q. Yang, P. G. Ranjith, and J. Zhao, "Strength failure behavior and crack evolution mechanism of granite containing pre-existing non-coplanar holes: experimental study and particle flow modeling," Computers and Geotechnics, vol. 88, pp. 182-198, 2017.

[18] Z. D. Liu, L. L. Gao, B. S. Xu, X. Z. Zhang, and C. Q. Zhang, "Study on loading rate-dependent property of different layers in articular cartilage based on abaqus," Applied Mechanics and Materials, vol. 395-396, no. 2, pp. 650-653, 2013.

[19] K. N. Feng, R. Dong, P. Zhu, F. Collins, Y. Bai, C. M. Wang et al., "Discussion: effect of strain rate on splitting tensile strength of geopolymer concrete," Magazine of Concrete Research, vol. 66, no. 16, pp. 825-835, 2014.

[20] C. Jiang, G. F. Zhao, J. Zhu, Y. X. Zhao, and L. Shen, "Investigation of dynamic crack coalescence using a gypsum-like 3d printing material," Rock Mechanics and Rock Engineering, vol. 49, no. 10, pp. 3983-3998, 2016.

[21] Y. Wang, R. Yang, and G. Zhao, "Influence of empty hole on crack running in pmma plate under dynamic loading," Polymer Testing, vol. 58, pp. 70-85, 2017.

[22] C. Zou, L. N. Y. Wong, J. L. Jin, and B. S. Gan, "Different mechanical and cracking behaviors of single-flawed brittle gypsum specimens under dynamic and quasi-static loadings," Engineering Geology, vol. 201, no. 4, pp. 71-84, 2016.

[23] L. Q. Liu, P. X. Liu, H. C. Wong, S. P. Ma, and Y. S. Guo, "Experimental investigation of three-dimensional propagation process from surface fault," Science in China Series D: Earth Sciences, vol. 51, no. 10, pp. 1426-1435, 2008.

[24] Z. Z. Liang, H. Xing, S. Y. Wang, D. J. Williams, and C. A. Tang, "A three-dimensional numerical investigation of the fracture of rock specimens containing a pre-existing surface flaw," Computers and Geotechnics, vol. 45, no. 45, pp. 19-33, 2012.

[25] H. Li and L. N. Y. Wong, "Influence of flaw inclination angle and loading condition on crack initiation and propagation," International Journal of Solids and Structures, vol. 49, no. 18, pp. 2482-2499, 2012.

[26] C. Jiang, G. F. Zhao, and N. Khalili, "On crack propagation in brittle material using the distinct lattice spring model," International Journal of Solids and Structures, vol. 118-119, pp. 41-57, 2017.

[27] Li Guo, J Xiang, J. P. Latham, and B. Izzuddin, “A numerical investigation of mesh sensitivity for a new three-dimensional fracture model within the combined finite-discrete element method," Engineering Fracture Mechanics, vol. 151, pp. 70-91, 2016.

[28] Y. F. Yang, C. A. Tang, and K. W. Xia, "Study on crack curving and branching mechanism in quasi-brittle materials under dynamic biaxial loading," International Journal of Fracture, vol. 177, no. 1, pp. 53-72, 2012.

[29] C. A. Tang and Y. F. Yang, "Crack branching mechanism of rock-like quasi-brittle materials under dynamic stress," Journal of Central South University, vol. 19, no. 11, pp. 3273-3284, 2012.

[30] C. Tang and C. Tang, "Numerical simulation of progressive rock failure and associated seismicity," International Journal of Rock Mechanics and Mining Sciences, vol. 34, no. 2, pp. 249-261, 1997.

[31] C. Zou, L. N. Y. Wong, J. L. Jin, and B. S. Gan, "Different mechanical and cracking behaviors of single-flawed brittle gypsum specimens under dynamic and quasi-static loadings," Engineering Geology, vol. 201, no. 4, pp. 71-84, 2016.

[32] X. Li, T. Zhou, and D. Li, "Dynamic strength and fracturing behavior of single-flawed prismatic marble specimens under impact loading with a split-hopkinson pressure bar," Rock Mechanics and Rock Engineering, vol. 50, no. 1, pp. 29-44, 2016.

[33] C. Zou, L. N. Y. Wong, and Y. Cheng, "The strength and crack behavior of the rock-like gypsum under high strain rate," in Proceedings of Arma, Us Rock Mechanics/Geomechanics Symposium, Chicago, IL, USA, June 2012.

[34] C. Zou and L. N. Y. Wong, "Experimental studies on cracking processes and failure in marble under dynamic loading," Engineering Geology, vol. 173, no. 5, pp. 19-31, 2014.

[35] S. Suzuki, K. Sakaue, and K. Iwanaga, "Measurement of energy release rate and energy flux of rapidly bifurcating crack in Homalite 100 and Araldite B by high-speed holographic microscopy," Journal of the Mechanics and Physics of Solids, vol. 55, no. 7, pp. 1487-1512, 2007.

[36] W. G. Shen, T. Zhao, G. B. Crosta et al., "Analysis of impactinduced rock fragmentation using a discrete element approach," International Journal of Rock Mechanics and Mining Sciences, vol. 98, pp. 33-38, 2017.

[37] X. Wu, Experimental and Numerical Study on Propagation Mechanism of Three-Dimensional Crack of Rock Specimens, Dalian University of Technology, Dalian, China, 2016, in Chinese. 


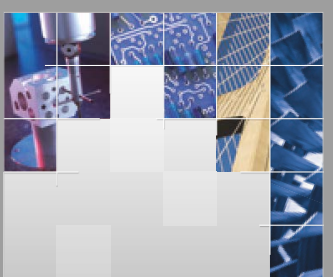

\section{Enfincering}
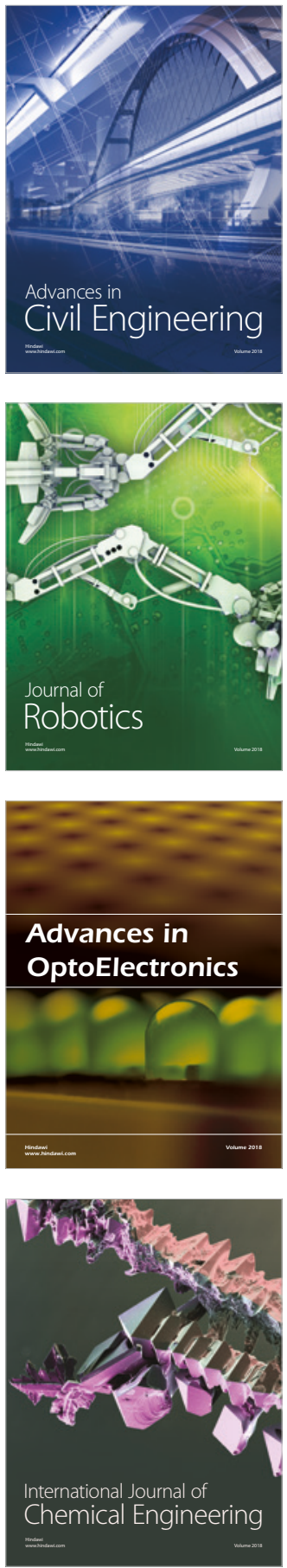

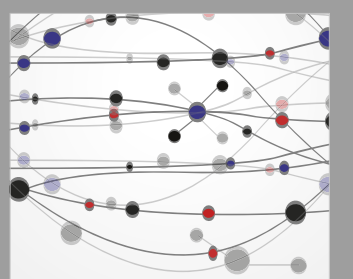

\section{Rotating \\ Machinery}

The Scientific World Journal

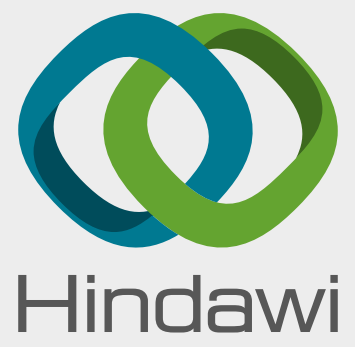

Submit your manuscripts at

www.hindawi.com
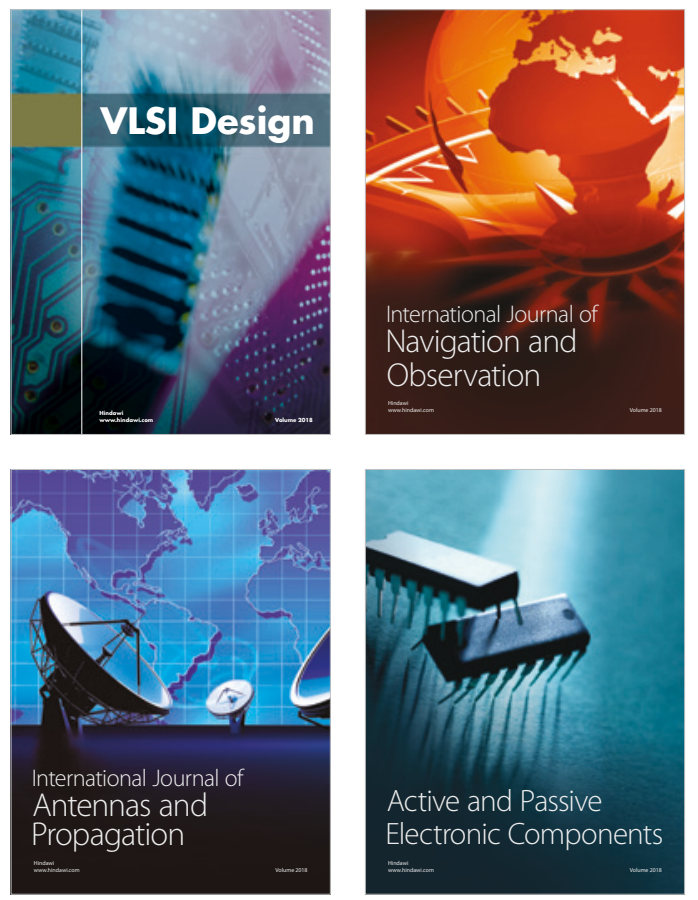
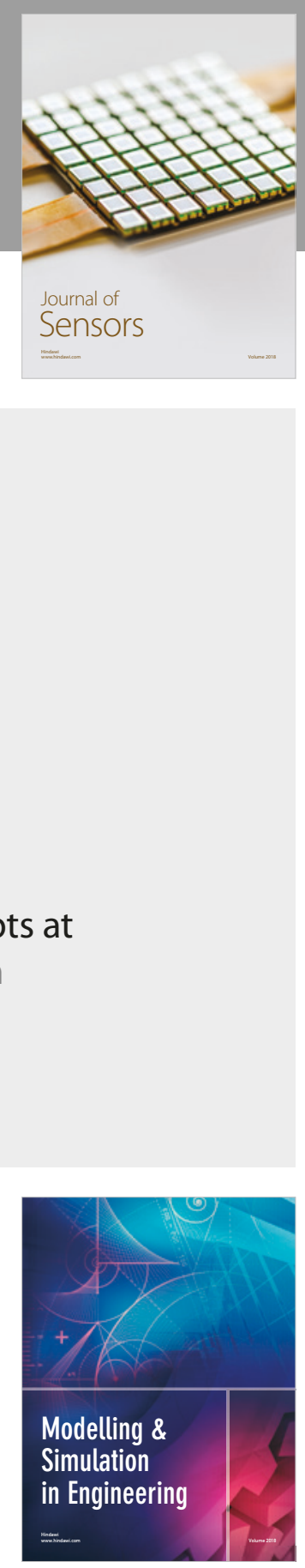

\section{Advances \\ Multimedia}
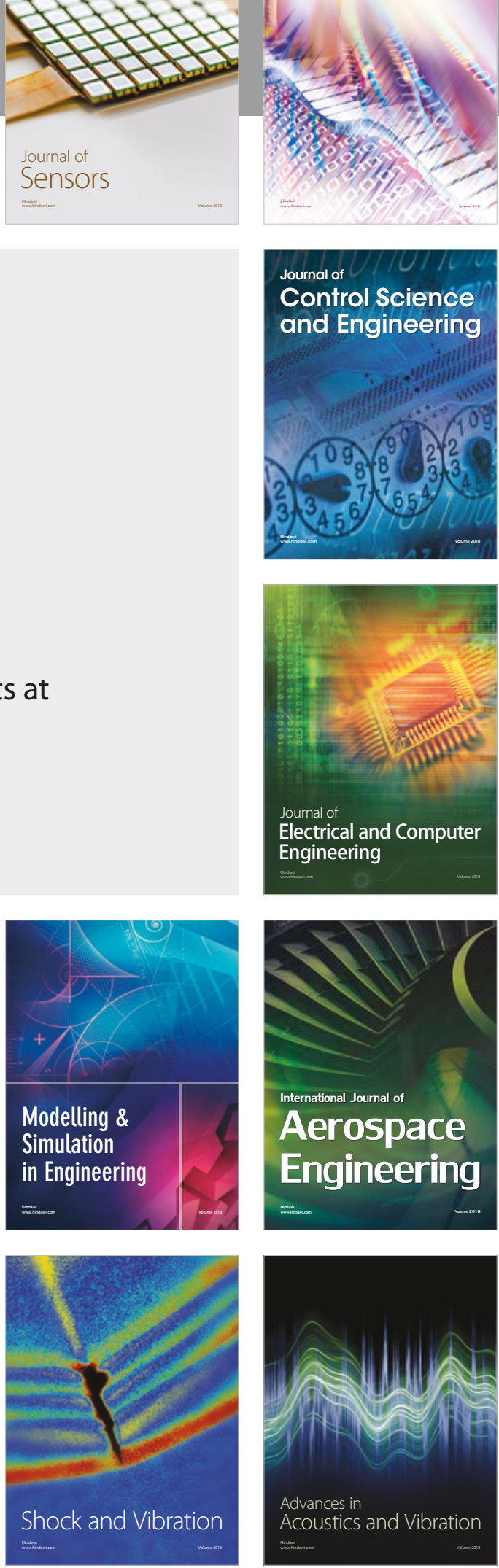